\title{
Responsabilidade social interna em uma cooperativa
}

\author{
Internal social responsibility in a cooperative
}

\begin{abstract}
Resumo
O objetivo deste artigo é identificar e avaliar práticas de Responsabilidade Social Interna (RSI) em uma cooperativa, da ótica de seus funcionários. Para o desenvolvimento da investigação assumiu-se que os indicadores de Responsabilidade Social (RS) estão próximos dos princípios cooperativistas. Assim sendo, as cooperativas devem atuar de forma responsável em relação a todos os seus stakeholders, desenvolvendo, com seus públicos externo e interno, práticas de gestão que podem ser identificadas a partir de Indicadores de Responsabilidade Social do Instituto Ethos (IRSIE). Trata-se de pesquisa descritiva, quali-quantitativa, aplicada, desenvolvida por meio de pesquisa de campo na unidade sede de uma cooperativa de crédito, no interior do estado de São Paulo. Os resultados alcançados apontam para a presença de práticas de RSI e indicam que a maioria dos funcionários identifica a presença de RS nas ações da cooperativa. No entanto, algumas ações e procedimentos devem ser aperfeiçoados e divulgados pela cooperativa.
\end{abstract}

Palavras-chave: responsabilidade social interna, cooperativa de crédito, indicadores ethos de responsabilidade social.

\begin{abstract}
The objective of this article is to identify and evaluate actions of Internal Social Responsibility (ISR) in a cooperative from the point of view of its employees. For the development of the research it was assumed that the indicators of Social Responsibility (SR) are close to the cooperativism principles. Therefore, cooperatives must act responsibly in relation to all their stakeholders, developing, with their external and internal stakeholders, good management practices that can be identified from the Ethos Institute's Social Responsibility Indicators (EISRI). This is a descriptive, qualitative and quantitative, applied research, developed through a field research in the headquarters unit of a credit cooperative, in the interior of the state of São Paulo. The results show the presence of ISR practices and indicate that the great majority of employees identify the presence of SR in the actions of the cooperative. However, some actions and procedures should be improved and disclosed by the cooperative.
\end{abstract}

Keywords: internal social responsibility, credit cooperative, ethos indicators of social responsibility.

Claudio Luis Piratelli ${ }^{\mathrm{I}}$, Cleber Marcelo de Lima ${ }^{\mathrm{II}}$, Jorge Alberto Achcar ${ }^{\mathrm{III}}$, Oriowaldo Queda ${ }^{\mathrm{IV}}$, Vera Mariza Henriques de Miranda Costav

${ }^{\text {I } U n i v e r s i d a d e ~ d e ~ A r a r a q u a r a, ~ B o l s i s t a ~ F U N A D E S P, ~ c l p i r a t e l l i @ u n i a r a . c o m . b r ~}$

${ }^{\text {II }}$ Fatec Bebedouro - Faculdade de Tecnologia Jorge Caram Sabbag; Universidade Norte do Paraná, UNOPAR. clebermarcelodelima@gmail.com

${ }^{\text {III }}$ Universidade de Araraquara, Bolsista CNPq, achcar@fmrp.usp.br

IV Universidade de Araraquara, Bolsista FUNADESP, quedaoriowaldo@gmail.com

${ }^{\mathrm{V}}$ Universidade de Araraquara, Bolsista FUNADESP, verammcosta@uol.com.br 


\section{Introdução}

Nos últimos anos, ganhou força a ideia de que as empresas de capital devem desenvolver ações éticas e responsáveis em relação a todos os grupos com os quais interagem e não apenas gerar lucros para acionistas. Assim sendo, tem-se difundido a discussão do conceito, das dimensões e manifestações de Responsabilidade Social - RS (GRAYSON; HODGES, 2002). Rendón-Cobián (2019) ressalta que os diversos tipos de organização apresentam particularidades que marcam seu funcionamento formal e sua dinâmica sociocultural, influenciando a forma pela qual assumem responsabilidades frente à sociedade. Assim sendo, várias expressões concretas da RS se manifestam em um plano tácito, combinado com argumentos de racionalidade formal.

Em contexto de discussão semelhante, são tratadas as especificidades das cooperativas, diferenciando a atuação delas dos procedimentos praticados pelas demais empresas. São reconhecidas as diferenças entre a empresa cooperativa e a não cooperativa - empresa de capital que se manifestam, dentre outros, nas características da tributação, nas relações entre stakeholders, nas especificidades na forma de organização e gestão. De acordo com os princípios cooperativistas, as cooperativas devem visar não apenas o bom desempenho econômico, mas também realizações de relevância social (BIALOSKORSKI NETO, 1998).

Apesar das diferenças entre a empresa não cooperativa e a cooperativa, observa-se a tendência à redução da distância entre elas, no processo de gestão e de relacionamento com seus stakeholders, tendo em vista a incorporação, pelas primeiras, de ações de RS. Bussler et al.(2017), embora tenham realizado recorte diferente do proposto no presente texto, avaliam que o conceito de RS envolve amplo conjunto de stakeholders e engloba tanto os impactos das atividade sobre a comunidade e o meio ambiente quanto a qualidade de vida e o bem-estar do público interno (PI) da empresa.

Tomando por referência os princípios que regem as empresas cooperativas, estas devem desenvolver, externa e internamente, ações que se identificam como de RS, o que torna o funcionário interno um público estratégico para os estudos voltados à observação da ligação entre o discurso empresarial e as suas relações trabalhistas (CRUZ et al., 2012).

A investigação que dá suporte ao presente artigo partiu do suposto de que as cooperativas, em razão dos princípios que as regem, desenvolvem boas práticas de gestão de pessoas e, muitas delas, em consonância com as práticas de RS. Tendo em vista a flexibilização da atuação das empresas cooperativas, aproximando-as de outras formas de organização empresarial, torna-se relevante a avaliação de ações de cooperativas para com seus stakeholders, no caso em questão, com seus próprios funcionários, utilizando instrumento de investigação elaborado a partir de questionário que parte dos Indicadores de Responsabilidade Social do Instituto Ethos (IRSIE).

A partir da questão: "Quais as principais práticas de Responsabilidade Social, com seu Público Interno (PI), podem ser identificadas em empresas cooperativas e quais poderiam ser intensificadas?" - foi proposta a investigação, definidos os objetivos e o universo da pesquisa.

Nesse contexto, constituiu objetivo principal da pesquisa que deu suporte ao presente artigo identificar e avaliar as práticas de Responsabilidade Social Interna (RSI), entre funcionários vinculados à sede de uma cooperativa, localizada no interior do estado de São Paulo, a partir da ótica de seus funcionários. Pretendeu-se, ainda, como objetivo secundário, avaliar a eficiência do instrumento utilizado para a identificação da incidência das referidas práticas, na cooperativa estudada, na percepção de seus funcionários.

Silva, Silva e Chiapinotto (2018) chamam a atenção para a estreita relação estabelecida entre o cooperativismo e a responsabilidade social, expressa em pesquisas realizadas no Brasil por Ba e 
Martins (2010); Caccia, Zarelli e Gimenes (2008); Cardoso e Nicoleti (2007); Gibbert e Bezerra (2007); Nishigawa, Gimenes e Gimenes (2007); Serra, Ferreira e Teixeira (2008); Souza e Laros, (2010).

Outros trabalhos (CANÇADO; SILVA JUNIOR; RIGO, 2008; CHAVES; VIEIRA; ROCHA, 2009; CANÇADO et al., 2012) tratam, lado a lado, cooperativas e ações de RS, considerando a atuação de empresas ou o tratamento dado a públicos internos e/ou externos, no entanto, com recorte e foco diferentes do realizado neste artigo.

Também, a percepção dos empregados, relativa a ações de RS em cooperativas, tem sido foco de outras investigações, caso dos trabalhos de Cardoso e Nicoleti (2007) e de Pontes et al. (2016). No entanto, a metodologia utilizada na pesquisa que deu suporte ao presente artigo, em razão, dentre outros, do tamanho da amostra, da configuração e abrangência do instrumento utilizado e do tratamento a que foram submetidas as informações levantadas, propiciou o alcance de resultados com maior grau de detalhamento das informações, do que os anteriormente referidos.

Cabe observar, em relação aos trabalhos citados nos parágrafos anteriores, sua maior presença na primeira década do século 21, reduzindo-se na segunda: 3 em 2007, 3 em 2008; 1 em 2009 e 2 em 2010. Na segunda década foram produzidos apenas 2: 1 em 2012 e 1 em 2016, o que justifica novas investigações nessa temática.

A pesquisa desenvolvida se justifica, ainda, dado que seus resultados poderão ser utilizados para o desenvolvimento de melhor relacionamento com o PI, na unidade pesquisada, aplicáveis em outras organizações cooperativas e também em empresas não cooperativas. Além do mais, por complementar investigações semelhantes, desenvolvidas, porém, com foco e metodologias diferentes.

O artigo está estruturado em cinco seções. Nesta primeira, introdução, é feita a contextualização da problemática, a formulação da questão pesquisa e dos objetivos, a breve indicação do universo e a justificativa para a realização da investigação. Na segunda, é feita a revisão bibliográfica sobre cooperativas, cooperativismo e responsabilidade social e realizada a identificação da proximidade, em termos de princípios norteadores, entre as categorias referidas. Na terceira, metodologia: a) é realizado o enquadramento metodológico da pesquisa; b) são caracterizados o universo pesquisado e o instrumento de investigação - questionário com afirmações - construído e utilizado para a percepção de ações de RSI na cooperativa estudada; c) é indicado o tratamento dado aos resultados. A quarta seção, intitulada "Responsabilidade Social Interna em uma cooperativa de crédito sob a ótica de seus funcionários", apresenta os resultados dos questionários aplicados. Na quinta seção são apresentadas as conclusões.

\section{COOPERATIVISMO E RESPONSABILIDADE SOCIAL}

\subsection{Cooperativismo}

Desde a fundação da primeira cooperativa em Rochdale, em 1844, os princípios doutrinários, que regem o cooperativismo e a atuação das empresas cooperativas têm sido objeto de discussão e de modificações.

O Quadro 1 apresenta, de maneira sintética, esses princípios doutrinários e sua evolução, desde Rochdale, em 1844, até a última revisão, realizada em 1995. 
Quadro 1 - Evolução dos Princípios Doutrinários do Cooperativismo (1844-1995)

\begin{tabular}{|l|l|l|l|}
\hline \multicolumn{1}{|c|}{ Rochdale, 1844 } & \multicolumn{1}{|c|}{ Paris, 1937 } & \multicolumn{1}{c|}{ Viena, 1966 } & \multicolumn{1}{c|}{ Manchester, 1995 } \\
\hline 1. Adesão Livre & 1. Adesão Livre & 1. Adesão Livre & $\begin{array}{l}\text { 1.Adesão voluntária } \\
\text { e livre }\end{array}$ \\
\hline $\begin{array}{l}\text { 2.Controle } \\
\text { democrático (cada } \\
\text { homem, um voto) }\end{array}$ & $\begin{array}{l}\text { 2.Gestão } \\
\text { democrática (cada } \\
\text { homem, um voto) }\end{array}$ & 2.Gestão democrática & 2.Gestão democrática \\
\hline $\begin{array}{l}\text { 3. Retorno das sobras } \\
\text { pro-rata } \\
\text { (proporcionais) às } \\
\text { operações }\end{array}$ & $\begin{array}{l}\text { 3.Retorno Pro Rata } \\
\text { às Operações }\end{array}$ & $\begin{array}{l}\text { 3. Distribuição das } \\
\text { Sobras para: a) } \\
\text { desenvolvimento da } \\
\text { cooperativa; b) } \\
\text { serviços comuns; c) } \\
\text { associados - pro-rata } \\
\text { às operações }\end{array}$ & $\begin{array}{l}\text { 3.Participação } \\
\text { econômica dos } \\
\text { associados }\end{array}$ \\
\hline $\begin{array}{l}\text { 4. Juro Limitado ao } \\
\text { Capital investido }\end{array}$ & $\begin{array}{l}\text { 4.Limitação dos } \\
\text { juros } \\
\text { sobre o capital }\end{array}$ & $\begin{array}{l}\text { 4. Taxa Limitada de } \\
\text { Juros ao Capital }\end{array}$ & $\begin{array}{l}\text { 4.Autonomia e } \\
\text { Independência das } \\
\text { cooperativas }\end{array}$ \\
\hline $\begin{array}{l}\text { 5. Educação dos } \\
\text { Membros }\end{array}$ & $\begin{array}{l}\text { 5. Promoção da } \\
\text { educação }\end{array}$ & $\begin{array}{l}\text { 5.Educação } \\
\text { cooperativista } \\
\text { permanente }\end{array}$ & $\begin{array}{l}\text { 5.Educação, } \\
\text { treinamento e } \\
\text { formação }\end{array}$ \\
\hline $\begin{array}{l}\text { 6. Vendas efetuadas } \\
\text { em Dinheiro }\end{array}$ & $\begin{array}{l}\text { 6. Compras e vendas } \\
\text { à vista }\end{array}$ & $\begin{array}{l}\text { 6.Cooperação entre } \\
\text { cooperativas }\end{array}$ & 6. Intercooperação \\
\hline $\begin{array}{l}\text { 7. Neutralidade } \\
\text { política, religiosa e } \\
\text { racial }\end{array}$ & $\begin{array}{l}\text { 7.Neutralidade } \\
\text { política, religiosa e } \\
\text { racial }\end{array}$ & $\begin{array}{l}\text { 7.Neutralidade } \\
\text { política, social, } \\
\text { religiosa e racial }\end{array}$ & $\begin{array}{l}\text { 7. Preocupação com } \\
\text { a Comunidade }\end{array}$ \\
\hline
\end{tabular}

Fonte: Elaborado a partir de Schneider (1999 e 2014); Cançado et al. (2012); OCB (2016)

Pode-se observar a flexibilização dos princípios, desde Rochdale, 1844 até Manchester, em 1995, passando por Paris, 1937 e Viena, 1966. Essa flexibilização, que se manifesta nos 7 princípios, fica bem evidente nas modificações por que passaram os princípios 2, 3, 6 e 7. No entanto, essa flexibilização deve preservar princípios e valores da cooperativa. Nos termos de Omar, Rosalem e BA (2019) as cooperativas são as instituições nas quais devem estar presentes o lado econômico e o social e essa dualidade de funções deve auxiliar os membros a entenderem melhor os princípios e os valores da cooperativa.

\subsection{Responsabilidade Social}

As avaliações de ações socialmente relevantes se fazem acompanhar, com freqüência, de discussões sobre ética e responsabilidade social. Segundo Leisinger e Schmitt (2001), até os anos 1950 o conceito de "ética empresarial" ainda não era objeto de atenção da academia e não havia entrado no vocabulário acadêmico. Foi no final da década de 1960, no conjunto das discussões das relações entre economia e sociedade, sobre os direitos dos trabalhadores e das minorias e, ainda, com as preocupações com os países "em desenvolvimento", que evoluíram as discussões que estimularam os interesses sobre ética empresarial. Finalmente nos anos 1970 foram propostas reflexões específicas sobre "ética empresarial", ao lado de, entre outras, "ética ambiental", "ética da mídia" e "ética da pesquisa".

Existem quatro obrigações expressas na RS: econômicas, legais, éticas e voluntárias que têm foco nos stakeholders e nas novas ideias sobre cidadania corporativa. As econômicas envolvem geração de riqueza, produtos e serviços de que a sociedade necessita. As legais se referem ao respeito às leis. As éticas envolvem o respeito aos padrões, normas ou expectativas, atendendo ao que os stakeholders consideram justo ou que protegem os direitos morais de todos. As voluntárias, não 
exigidas pelas leis, demonstram compromisso de cidadania, apoiando os objetivos sociais da comunidade (CARROLL, 1991).

A Responsabilidade Social Empresarial (RSE) é uma ferramenta de gestão que permite à organização desenvolver ações com o objetivo de minimizar os efeitos negativos que suas atividades podem ter sobre a comunidade, o meio ambiente e a economia (COSTA, 2007).

Melo Neto e Froes (2002) apresentam a RS como a prática da "cidadania corporativa", que presume o desempenho da empresa em dois âmbitos: interno e externo, conforme apresentado no Quadro 2.

Quadro 2 - Responsabilidade Social Interna e Externa

\begin{tabular}{|l|l|l|}
\cline { 2 - 3 } \multicolumn{1}{c|}{} & \multicolumn{1}{c|}{$\begin{array}{c}\text { Responsabilidade Social Interna } \\
\text { (RSI) }\end{array}$} & \multicolumn{1}{c|}{$\begin{array}{c}\text { Responsabilidade Social } \\
\text { Externa (RSEx) }\end{array}$} \\
\hline Foco & $\begin{array}{l}\text { Público Interno (funcionários e seus } \\
\text { dependentes) }\end{array}$ & Comunidade \\
\hline $\begin{array}{l}\text { Áreas de } \\
\text { Atuação }\end{array}$ & $\begin{array}{l}\text { Educação, Salários e Benefícios; } \\
\text { Assistência Médica, Social e } \\
\text { Odontológica }\end{array}$ & $\begin{array}{l}\text { Educação, Saúde, Assistência } \\
\text { Social e Ecológica }\end{array}$ \\
\hline Instrumentos & $\begin{array}{l}\text { Programa de RH / Planos de } \\
\text { Previdência Complementar }\end{array}$ & $\begin{array}{l}\text { Doações, Programa de } \\
\text { Voluntariado, Parcerias, } \\
\text { Programas e Projetos Sociais }\end{array}$ \\
\hline $\begin{array}{l}\text { Tipo de } \\
\text { Retorno }\end{array}$ & De Produtividade e para os Acionistas & $\begin{array}{l}\text { Social, de imagem, Publicitário e } \\
\text { para os Acionistas }\end{array}$ \\
\hline
\end{tabular}

Fonte: Melo Neto e Froes (2002).

O Instituto Ethos (2016), organização não governamental, criada com a missão de mobilizar, sensibilizar e auxiliar todos os tipos de organizações a gerirem seus negócios de forma socialmente responsável tem, dentre seus encargos, a organização dos Indicadores Ethos de Responsabilidade Social. Esses indicadores, organizados em sete temas - Valores, Transparência e Governança; Público Interno; Meio Ambiente; Fornecedores; Consumidores e Clientes; Comunidade; Governo e Sociedade - representam uma ferramenta que auxilia as empresas no processo de aprofundamento e de comprometimento com o modelo de gestão responsável, sendo um guia para organizações que procuram por esse modelo. Os indicadores estão estruturados em forma de questionário, compreendendo toda a teia de relacionamento da organização com seus diversos públicos (ETHOS, 2016). A partir desses indicadores foi estruturado o questionário utilizado pela investigação que dá suporte a este artigo.

\subsection{Cooperativismo, Cooperativas e Responsabilidade Social}

A Responsabilidade Social não é algo novo para as cooperativas. No cumprimento dos princípios cooperativistas as cooperativas desenvolvem a gestão junto à comunidade, visando o cumprimento de funções sociais que, em última análise, se aproximam das ações de Responsabilidade Social (CHAVES; VIEIRA; ROCHA, 2009).

O Quadro 3 apresenta a proximidade entre os princípios cooperativistas e os indicadores de RS elaborados pelo Instituto Ethos (ETHOS, 2016). Na primeira coluna estão os princípios cooperativistas, numerados de 1 a 7 e na segunda os indicadores de RS considerados próximos aos princípios cooperativistas, apresentados na primeira coluna. 
Quadro 3 - Articulação dos Princípios Cooperativistas com Indicadores de RS do Instituto Ethos

\begin{tabular}{|c|c|}
\hline Princípios do Cooperativismo & $\begin{array}{c}\text { Indicadores de Responsabilidade Social } \\
\text { - Instituto Ethos }\end{array}$ \\
\hline $\begin{array}{l}1 \text { - Adesão Voluntária e Livre } \\
\text { Sem discriminação social, racial, política ou } \\
\text { religiosa e de sexo. }\end{array}$ & $\begin{array}{l}\text { Compromissos éticos. Valorização da } \\
\text { diversidade. Compromisso com a não } \\
\text { discriminação e promoção da equidade racial. } \\
\text { Compromisso com a promoção da equidade de } \\
\text { sexo. }\end{array}$ \\
\hline $\begin{array}{l}2 \text { - Gestão Democrática } \\
\text { Controladas pelos seus membros, as cooperativas } \\
\text { participam na formulação das políticas e na } \\
\text { tomada de decisões. } \\
\text { Há igual direito de voto (um membro, um voto). }\end{array}$ & $\begin{array}{l}\text { Relação com os sindicatos. Gestão participativa. } \\
\text { Política de remuneração, benefícios e carreira. } \\
\text { Balanço social. Preparação para aposentadoria. } \\
\text { Relação com os trabalhadores terceirizados. } \\
\text { Comportamento nas demissões. Práticas } \\
\text { anticorrupção e antipropina. Contribuição para } \\
\text { campanhas políticas. }\end{array}$ \\
\hline $\begin{array}{l}\text { 3- Participação econômica dos cooperados } \\
\text { Contribuição igual para o capital das cooperativas, } \\
\text { destinação dos excedentes a uma ou mais } \\
\text { finalidades, visando o desenvolvimento da } \\
\text { cooperativa, possibilitando a formação de reservas } \\
\text { ou o retorno aos associados. }\end{array}$ & $\begin{array}{l}\text { Enraizamento na Cultura Organizacional. } \\
\text { Diálogo e engajamento das partes interessadas. } \\
\text { Minimização da entrada e saídas de materiais. }\end{array}$ \\
\hline $\begin{array}{l}\text { 4- Autonomia e independência } \\
\text { Conjugação de esforços do quadro social. } \\
\text { Autogestão, sucesso ou insucesso afetam } \\
\text { unicamente associados. Em razão da gestão ser } \\
\text { exclusividade dos associados, não se cogita de } \\
\text { influência externa, especialmente para assegurar } \\
\text { privilégios em detrimento da coletividade de } \\
\text { cooperados. }\end{array}$ & $\begin{array}{l}\text { Governança Corporativa. Critérios de avaliação e } \\
\text { seleção de fornecedores. Excelência no } \\
\text { atendimento. }\end{array}$ \\
\hline $\begin{array}{l}5 \text { - Educação, formação e informação } \\
\text { As cooperativas promovem educação, formação e } \\
\text { informação entre os diferentes públicos internos e } \\
\text { a conscientização do público em geral, incluindo } \\
\text { os setores oficiais implicados, sobre as } \\
\text { especificidades e os apelos do cooperativismo. }\end{array}$ & $\begin{array}{l}\text { Compromisso com: o futuro das crianças, o } \\
\text { desenvolvimento infantil e profissional e com a } \\
\text { empregabilidade. Educação e conscientização } \\
\text { ambiental. Relações com organizações locais. } \\
\text { Compromisso com a melhoria da qualidade } \\
\text { ambiental. Gerenciamento dos impactos sobre o } \\
\text { meio ambiente e o ciclo de vida dos produtos e } \\
\text { serviços. Sustentabilidade da economia florestal. } \\
\text { Conhecimento e gerenciamento dos danos } \\
\text { potenciais dos produtos e serviços. }\end{array}$ \\
\hline $\begin{array}{l}6 \text { - Intercooperação } \\
\text { Cooperação entre cooperativas, servindo de forma } \\
\text { eficaz seus membros e dando força ao movimento } \\
\text { cooperativo, trabalhando em conjunto, através das } \\
\text { estruturas locais, regionais, nacionais e } \\
\text { internacionais. }\end{array}$ & $\begin{array}{l}\text { Relações com a concorrência. } \\
\text { Apoio ao desenvolvimento de fornecedores. }\end{array}$ \\
\hline $\begin{array}{l}7 \text { - Interesse pela comunidade } \\
\text { As cooperativas trabalham para o } \\
\text { desenvolvimento sustentado das } \\
\text { suas comunidades através de políticas aprovadas } \\
\text { pelos membros. }\end{array}$ & $\begin{array}{l}\text { Cuidados com saúde, segurança e condições de } \\
\text { trabalho. Política de comunicação social. } \\
\text { Gerenciamento do impacto da empresa na } \\
\text { comunidade. Envolvimento com a ação social. } \\
\text { Liderança e influência social. Participação de } \\
\text { projetos sociais governamentais. Construção da } \\
\text { cidadania pelas empresas. Atenção e combate ao } \\
\text { trabalho infantil e ao trabalho forçado na cadeia } \\
\text { produtiva. }\end{array}$ \\
\hline
\end{tabular}

Fonte: Elaborado pelos autores a partir de OCB (2016), Ethos (2016) e Portal do Cooperativismo Financeiro (2016). 
Outros estudos sobre RS e/ou Cooperativas, alguns já referidos na Introdução deste artigo, foram desenvolvidos, nos últimos anos, sob vários enfoques, justificando o recorte ora pretendido e subsidiando a presente investigação. São eles os textos de: Cardoso e Nicoleti (2007), Cançado, Silva Júnior e Rigo (2008), Noriler e Machado (2008), Serra, Ferreira e Teixeira (2008), Chaves, Vieira e Rocha (2009), Queiroz (2009), Souza et al. (2013), Lazzareschi, Alves e Bonelli (2016) e Pontes et al.(2016). Seus títulos expressam o recorte utilizado pelos autores.

Cabe destaque especial a alguns deles. Cançado, Silva Júnior e Rigo (2008) avaliaram que o princípio "Preocupação com a Comunidade", geralmente entendido como RS para as Cooperativas, apresenta importantes diferenças em relação à RS praticada pelas empresas mercantis. Queiroz (2009), a partir da aplicação, em duas empresas mineiras, de questionário construído a partir de indicadores do Instituto Ethos, para verificar a percepção de trabalhadores, de gestores e de sindicalistas, pôde captar algumas falhas dessas empresas no que diz respeito à implantação de ações de RS. Noriler e Machado (2008) analisaram a condução da RS em uma cooperativa de crédito, fazendo uso de um questionário baseado nos Indicadores do Instituto Ethos, num procedimento semelhante ao adotado pela pesquisa que deu suporte ao presente artigo. Segundo os autores, a cooperativa conseguiu identificar plenamente seus valores e princípios, porém faltou a implementação de melhorias perante o PI. Também Souza et al. (2013), com o objetivo de analisar a relação entre RS e qualidade de vida no trabalho, utilizaram instrumento construído a partir de questionário do Instituto Ethos e o aplicaram em empregados de uma empresa não cooperativa, uma operadora de planos de saúde. Os resultados obtidos por Souza et al. (2013) indicam fragilidade no cumprimento dos princípios de RS para com o PI. Segundo percepção e declaração de um dos respondentes da pesquisa, o treinamento está mais centrado no desempenho da empresa do que na satisfação dos empregados.

\section{METODOLOGIA}

A pesquisa realizada se enquadra, segundo conceito de Turrioni e Mello (2012), quanto aos objetivos, como descritiva e quanto à natureza como aplicada e, nos termos de Martins (2010), quanto à abordagem e ao tratamento dos dados, como quali-quantitativa. No que diz respeito ao tipo ou estratégia de pesquisa, trata-se de uma pesquisa de campo (BERTO; NAKANO, 2000 e 2014).

A investigação foi desenvolvida na unidade sede - matriz - de uma cooperativa de crédito, situada no interior do estado de São Paulo. Com 34 anos de existência, em 2017, a área de atuação da cooperativa escolhida abrange mais de 150 municípios no estado de São Paulo e no Sul de Minas Gerais, conta com 75.000 cooperados e 795 funcionários e abriga, além da matriz - objeto da investigação - mais 58 filiais. Para o cumprimento dos objetivos propostos, a pesquisa poderia ser desenvolvida em qualquer outro dos 13 ramos do cooperativismo presentes, no Brasil, até 2019 (OCB, 2019): Agropecuário, Consumo, Crédito, Educacional, Especial, Habitacional, Infraestrutura, Mineral, Produção, Saúde, Trabalho, Transporte, Turismo e Lazer. A escolha da unidade, do ramo de crédito, foi feita em razão de possibilidade de acesso de um dos autores do artigo. Dados e informações foram levantados na documentação da cooperativa selecionada e através de aplicação de questionário aos funcionários.

O questionário foi elaborado a partir dos Indicadores de Responsabilidade Social do Instituto Ethos - IRSIE (ETHOS, 2014), para ser aplicado a funcionários ocupando diversos cargos.

Desde 2000, o Instituto Ethos elabora os Indicadores Ethos de Responsabilidade Social, na forma de um questionário, para apoiar as empresas em um processo de auto avaliação, com o objetivo de melhorar a sua atuação no que diz respeito à RS. Os Indicadores, propostos para todos os tipos de empresas e negócios, abrangem vários stakeholders, como consumidores, fornecedores, acionistas e Governo, além do Público Interno, utilizado como referência neste artigo.

O questionário original apresenta divisões em blocos de temas e subtemas chamados de estágios e as afirmações devem ser indicadas apenas com as alternativas "sim" e "não". Visando sua 
aplicação na cooperativa de crédito, optou-se por não utilizar o questionário do Instituto Ethos, em sua totalidade, sendo retirados temas não relacionados ao contexto e aos objetivos da pesquisa que deu suporte ao presente artigo, bem como realizar adaptações e ampliação de alternativas para as afirmações propostas.

O questionário aplicado foi estruturado em 7 blocos de $A_{1}$ a A7, abrangendo 64 afirmações. Para a estruturação das 56 primeiras, distribuídas pelos seis blocos iniciais, foram utilizados, com adaptações, os Indicadores do Instituto Ethos (ETHOS, 2014). Esses indicadores abrangem relações sindicais, remuneração e benefícios, compromisso com o desenvolvimento profissional, comportamento frente a demissões e empregabilidade, saúde, segurança no trabalho, condições de trabalho, qualidade de vida e jornada de trabalho. Um $7^{\mathbf{o}}$ bloco, com 8 afirmações, foi estruturado a partir da experiência dos autores, com o objetivo de comparar a atuação de cooperativas de crédito com a de outras instituições financeiras, tendo por referência indicadores de RS.

As adaptações feitas no questionário de indicadores do Instituto Ethos, na parte aplicada ao PI, objetivaram redução significativa do número de questões e adequação das expressões empregadas, a fim de tornar o instrumento igualmente compreensivo para todos os funcionários, independentemente de seu nível de instrução e ocupação. Foi dada a possibilidade de oito alternativas a serem assinaladas, em lugar de apenas as opções SIM ou NÃO, adotadas pelo questionário original, do Instituto Ethos. Foi apresentada a escala de o a 5, sendo o para "não" e de 1 a 5 de menor para maior concordância e também as opções de não sabe "NS" e a de não quer responder "NQR", com o objetivo de utilização de estatística descritiva.

Dessa forma, objetivou-se apreender e dimensionar o nível de conhecimento dos funcionários, relativo à presença de ações de RS na cooperativa, "refinando" os resultados da presente investigação, em relação a outras semelhantes.

Além do posicionamento relativo às 64 afirmações, o questionário levantou informações sobre sexo, faixa etária e maior nível de instrução, diferenciando, dentre os funcionários, os gerentes.

A amostra foi selecionada por conveniência, por meio de convite aos participantes que se dispuseram participar da pesquisa, reunidos em grupos, em espaço próximo ao local de exercício de suas atividades. A aplicação, autorizada pela direção da cooperativa, foi realizada durante o mês de março de 2017, pelo pesquisador responsável por ela, que apresentou os objetivos da pesquisa e esclareceu sobre a livre adesão de participação e a garantia de não identificação dos respondentes. Após o questionário em mãos dos respondentes, foi explicada a sistemática de preenchimento, também explicitada no cabeçalho de cada questionário distribuído. Solicitou-se assinalar para cada afirmação uma das 8 alternativas propostas: o (zero) para Não; de 1 a 5 para Sim, esclarecendo ser a 1 a de menor concordância e a 5 de maior concordância; NS no caso de Não Saber (não ter conhecimento sobre o afirmado) e NQR no caso de Não Querer Responder.

O questionário foi respondido por 141 dos 280 funcionários, ocupando diversos cargos e por 9 dos 10 gerentes vinculados à matriz da cooperativa. Os registros relativos à percepção dos funcionários foram tabulados, considerando a quantidade de respostas para cada alternativa, posteriormente, transformados em percentuais e apresentados nas Tabelas: de 2 a 8. Por serem apenas 9 gerentes, as manifestações deles, também objeto de tratamento quantitativo, não foram apresentadas em tabelas, sendo apenas objeto de indicação no confronto com as posições dos demais funcionários.

Os dados coletados foram analisados qualitativa e quantitativamente, de forma a caracterizar o PI e identificar as práticas de RS da cooperativa para com esse público, sob a ótica dos funcionários. Para início da análise foi utilizada a estatística descritiva, área de estatística que apresenta métodos para organizar, resumir, comparar e descrever dados por meio de tabelas, gráficos e medidas de resumo e, para isso, foi utilizado o Software Minitab ${ }^{\circledR}$ v. 17 . Ainda com o auxílio do Software Minitab ${ }^{\circledast}$ v. 17 realizou-se o teste ANOVA (Análise de Variância), para comparar médias 
amostrais em função de categorias. Conforme Vieira (2016), a análise de variância (ANOVA) é um método estatístico que permite identificar diferenças entre médias de duas ou mais amostras. As suposições necessárias (normalidade e variância constante dos resíduos) para o uso do modelo ANOVA foram verificadas a partir de gráficos de resíduos fornecidos pelo software Minitab. A análise qualitativa das informações obtidas apoiou-se no referencial teórico utilizado e no confronto com resultados de investigações semelhantes.

\section{RESPONSABILIDADE SOCIAL INTERNA EM UMA COOPERATIVA DE CRÉDITO SOB A ÓTICA DE SEUS FUNCIONÁRIOS}

Os resultados sobre o perfil dos funcionários estão apresentados por sexo, faixa etária e nível de instrução e os referentes à identificação pelos funcionários da prática de RS pela cooperativa estão organizados de acordo com os sete blocos do questionário aplicado. Essa forma de apresentação retrata a estrutura do questionário, o que possibilita a replicação dele por parte de pesquisador(es) interessado(s). Também foi realizada a verificação de diferenças entre as opiniões médias dos respondentes por categoria (sexo, idade, instrução, gestores e funcionários).

\subsection{Distribuição dos funcionários por sexo, faixa etária e maior nível de instrução}

A distribuição da amostra por faixa etária dos 85 homens e das 56 mulheres está apresentada na Tabela 1.

Tabela 1 Distribuição da amostra por faixa etária, sexo e nível de instrução

\begin{tabular}{|c|c|c|c|c|c|}
\hline $\begin{array}{l}\text { Faixa etária } \\
\text { (anos) }\end{array}$ & Homens & Mulheres & Instrução & Homens & Mulheres \\
\hline Menos de 20 & 4 & 9 & Doutorado & o & o \\
\hline De 20 a 24 & 10 & 9 & Mestrado & 2 & o \\
\hline De 25 a 29 & 17 & 10 & Pós-graduação & 41 & 31 \\
\hline De 30 a 34 & 25 & 19 & Superior completo & 28 & 14 \\
\hline De 35 a 39 & 13 & 7 & Superior incompleto & 10 & 7 \\
\hline De 40 a 44 & 8 & 2 & Médio completo & 3 & 3 \\
\hline De 45 a 49 & 4 & o & Médio incompleto & 1 & 1 \\
\hline De 50 a 54 & 3 & o & Fundamental completo & o & o \\
\hline 55 ou mais & 1 & o & $\begin{array}{l}\text { Fundamental } \\
\text { incompleto }\end{array}$ & o & o \\
\hline Total & 85 & 56 & & 85 & 56 \\
\hline
\end{tabular}

Fonte: Elaborada pelos autores

É alto o nível de instrução dos funcionários de ambos os sexos: todos apresentam formação acima do fundamental, registrando-se funcionários com especialização e 2 com mestrado. Dessa forma, justifica-se a utilização da perspectiva dos funcionários para a identificação de práticas de RS presentes na cooperativa estudada. 


\subsection{A atuação da cooperativa em relação à presença de indicadores de Responsabilidade Social sob a ótica dos funcionários}

Os resultados, em percentuais, compõem as tabelas de 2 a 8 , a partir das afirmações dos funcionários, distribuídas por sete blocos e dessa forma apresentadas por ocasião da aplicação dos questionários.

Tabela 2 - Atuação da cooperativa frente a condições e contratos de trabalho e às relações sindicais

(Bloco A1 - Afirmações de 1 a 8)

\begin{tabular}{|c|c|c|c|c|c|c|c|c|c|}
\hline № & Afirmações & $\mathbf{0}$ & 1 & 2 & 3 & 4 & 5 & NS & NQR \\
\hline 1 & $\begin{array}{l}\text { Desenvolve programas que visam } \\
\text { melhorias das condições de trabalho de } \\
\text { seus empregados. }\end{array}$ & 1,5 & 3,8 & 5,3 & 12,9 & 28,8 & 47,7 & o & o \\
\hline 2 & $\begin{array}{l}\text { Participa de programas de avaliação ou } \\
\text { premiação de suas práticas de relações } \\
\text { de trabalho, para adaptar-se às melhores } \\
\text { práticas do mercado. }\end{array}$ & 6,1 & 6,1 & 8,3 & 17,4 & 19,7 & 31,1 & 10,6 & 0,8 \\
\hline 3 & $\begin{array}{l}\text { É reconhecida no mercado por suas } \\
\text { práticas de gestão de empregados, } \\
\text { recebendo prêmios ou selos que atestam } \\
\text { ser um dos melhores lugares para } \\
\text { trabalhar. }\end{array}$ & 3,8 & 1,5 & 4,5 & 17,4 & 20,5 & 45,5 & 6,8 & o \\
\hline 4 & $\begin{array}{l}\text { Permite que seus empregados afiliem-se } \\
\text { a sindicatos, sem restrições. }\end{array}$ & 3,0 & 3,0 & 3,0 & 5,3 & 12,9 & 43,9 & 28,0 & 0,8 \\
\hline 5 & $\begin{array}{l}\text { Acompanha e avalia se as obrigações } \\
\text { com os sindicatos sempre estão em dia e } \\
\text { são respeitadas. }\end{array}$ & 2,3 & 1,5 & 3,8 & 5,3 & 15,9 & 39,4 & 31,8 & o \\
\hline 6 & $\begin{array}{l}\text { Permite que sejam realizadas reuniões } \\
\text { sindicais no local de trabalho. }\end{array}$ & 1,5 & 2,3 & 4,5 & 6,1 & 13,6 & 49,2 & 22,7 & o \\
\hline 7 & $\begin{array}{l}\text { Possui acordos coletivos negociados } \\
\text { periodicamente com os sindicatos. }\end{array}$ & o & 1,5 & 1,5 & 8,3 & 15,9 & 62,1 & 9,1 & 1,5 \\
\hline 8 & $\begin{array}{l}\text { Mantém parcerias para cursos de } \\
\text { capacitação ou escolarização junto a } \\
\text { sindicatos. }\end{array}$ & 10,6 & 3,8 & 6,8 & 7,6 & 8,3 & 25,0 & 35,6 & 2,3 \\
\hline \multicolumn{2}{|r|}{ TOTAL (\%) } & 3,6 & 2,9 & 4,7 & $10, \mathbf{0}$ & 16,9 & 43,0 & 18,1 & 0,7 \\
\hline
\end{tabular}

Fonte: Elaborada pelos autores

A análise da Tabela 2 aponta alta incidência na indicação de maior concordância (5) para a maioria das afirmações, variando de $31,1 \%$ a $62,1 \%$, indicando a atenção da empresa para com as condições de emprego. A exceção, em relação à maior incidência na indicação do grau de concordância 5, está na afirmação 8 sobre parcerias com sindicatos para capacitação ou escolarização, em relação à qual predomina NS. Também se observa alta incidência de NS para as afirmações 4, 5 e 6 . Para o conjunto da Tabela 2, constata-se alto percentual de funcionários que avaliam positivamente as condições de trabalho e as relações sindicais. A análise das afirmações dos 9 gerentes indica ótica muito próxima à dos demais funcionários e sem grande variação entre os sexos masculino e feminino. 
Tabela 3 - Atuação da cooperativa referente a obrigações trabalhistas, salariais e benefícios - (Bloco A2 Afirmações de 9 a 20)

\begin{tabular}{|c|c|c|c|c|c|c|c|c|c|}
\hline № & Afirmações & $\mathbf{0}$ & $\mathbf{1}$ & 2 & 3 & 4 & 5 & NS & NQR \\
\hline 9 & $\begin{array}{l}\text { Cumpre com todas as obrigações legais } \\
\text { trabalhistas no que se refere ao } \\
\text { pagamento de salários e benefícios. }\end{array}$ & o & o & 0,8 & o & 3,0 & 96,2 & o & o \\
\hline 10 & $\begin{array}{l}\text { Respeita e cumpre as convenções } \\
\text { coletivas em que seus empregados estão } \\
\text { enquadrados. }\end{array}$ & $\mathrm{o}$ & $\mathrm{o}$ & 1,5 & 1,5 & 4,5 & 91,0 & 1,5 & $\mathrm{o}$ \\
\hline 11 & $\begin{array}{l}\text { Nos últimos anos aumentou o menor } \\
\text { salário em relação ao salário mínimo } \\
\text { vigente. }\end{array}$ & 0,8 & 0,8 & 1,5 & 2,3 & 9,8 & 62,9 & 20,4 & 1,5 \\
\hline 12 & Possui política de remuneração. & 3,0 & 3,8 & 7,6 & 6,1 & 13,6 & 58,3 & 4,5 & 3,0 \\
\hline 13 & $\begin{array}{l}\text { Possui procedimentos formais e claros de } \\
\text { promoção e aumento salarial. }\end{array}$ & 8,3 & 12,1 & 8,3 & 12,1 & 16,7 & 38,6 & 3,8 & o \\
\hline 14 & $\begin{array}{l}\text { Tem metas para diminuir a variação } \\
\text { proporcional entre o maior e o menor } \\
\text { salário. }\end{array}$ & 6,8 & 3,8 & 6,8 & 16,7 & 12,9 & 12,9 & 34,8 & 5,3 \\
\hline 15 & $\begin{array}{l}\text { É reconhecida pelo mercado por suas } \\
\text { práticas de remuneração. }\end{array}$ & 3,8 & 3,8 & 6,1 & 8,3 & 19,7 & 40,9 & 15,9 & 1,5 \\
\hline 16 & $\begin{array}{l}\text { Avalia o desempenho dos empregados de } \\
\text { maneira sistemática, pelo menos uma vez } \\
\text { ao ano. }\end{array}$ & 1,5 & 4,5 & 4,5 & 7,6 & 16,7 & 60,6 & 4,5 & $\mathrm{o}$ \\
\hline 17 & $\begin{array}{l}\text { O programa de participação nos } \\
\text { resultados ou de bonificação foi } \\
\text { estabelecido por meio de negociação com } \\
\text { uma comissão de empregados ou } \\
\text { sindicato e em conformidade com a } \\
\text { legislação aplicável. }\end{array}$ & o & 2,3 & 3,0 & 4,5 & 12,9 & 62,9 & 12,9 & 1,5 \\
\hline 18 & $\begin{array}{l}\text { É flexível frente às necessidades pessoais } \\
\text { doso empregados no planejamento do } \\
\text { trabalho. }\end{array}$ & 1,5 & 2,3 & 4,5 & 8,3 & 19,7 & 61,4 & 1,5 & 0,8 \\
\hline 19 & $\begin{array}{l}\text { Oferece seguro de vida, plano de saúde ou } \\
\text { outro(s) benefício(s) securitário(s) aos } \\
\text { seus empregados. }\end{array}$ & $\mathrm{o}$ & $\mathrm{o}$ & $\mathrm{o}$ & 2,3 & 4,5 & 93,2 & $\mathrm{o}$ & $\mathrm{o}$ \\
\hline 20 & $\begin{array}{l}\text { Oferece benefícios que abrangem os } \\
\text { familiares, como participação em plano } \\
\text { odontológico, de saúde, bolsas de estudo, } \\
\text { opções de lazer etc. }\end{array}$ & 1,5 & o & 6,1 & 7,6 & 13,6 & 69,7 & 1,5 & o \\
\hline \multicolumn{2}{|c|}{ TOTAL (\%) } & 2,3 & 2,8 & 4,2 & 6,4 & 12,3 & 62,4 & 8,5 & $\mathbf{1 , 1}$ \\
\hline
\end{tabular}

Fonte: Elaborada pelos autores

Exceção feita às afirmações 13, 14 e 15, para as demais foi registrada a maior concordância, superior a $50 \%$ e, em dois casos, com mais de $90 \%$, indicando percepção da RS pelo PI, relativa a obrigações trabalhistas, salariais e benefícios. Diante da afirmação 13: sobre procedimentos de promoção e aumento salarial, $38,6 \%$ assinalaram 5, porém $8,3 \%$ responderam o (zero) e $12,1 \%$ responderam 1. Dada a discrepância quanto à existência de procedimentos formais e claros, essa percepção deve ser considerada e avaliada pela cooperativa. Quanto à manifestação dos gerentes: em relação à afirmativa 13: 33,3\% assinalaram o (zero), o que indica a necessidade de tratamento dessa questão por parte da cooperativa. Essa foi a afirmativa que teve a maior variação dos gerentes em relação à indicação dos demais funcionários. 
Cardoso e Nicoleti (2007), ao analisarem o caso da BLUCREDI - Cooperativa de Economia e de Crédito Mútuo dos Servidores Públicos do Vale do Itajaí, apontam aspectos de RS promovidos pelas cooperativas e reconhecem a presença de ações, no entanto, isoladas e aleatórias e que, portanto, precisam ser fortalecidas. Pode ser este, também, o caso da cooperativa pesquisada.

Garcia e Weber (2019) analisaram processos trabalhistas em catorze cooperativas agropecuárias da região central do Estado do Rio Grande do Sul, referentes ao período de agosto de 2007 a agosto de 2017 e localizaram diversos tipos de processos, que podem contribuir para a identificação de falhas ao interior das cooperativas. Para a conscientização e prevenção de casos semelhantes, seria relevante a aplicação de questionário, nos moldes do utilizado na investigação em questão, a fim de captar possíveis falhas, e/ou propor a implantação de discussões relativas a obrigações trabalhistas, salariais e benefícios.

Tabela 4 - Atuação da cooperativa referente a condições de trabalho e treinamento (Bloco $\mathrm{A}_{3}$ Afirmações de 21 a 30)

\begin{tabular}{|c|c|c|c|c|c|c|c|c|c|}
\hline № & Afirmações & $\mathbf{o}$ & $\mathbf{1}$ & 2 & 3 & 4 & 5 & NS & NQR \\
\hline 21 & $\begin{array}{l}\text { Atrai profissionais e é procurada pelas suas } \\
\text { condições de trabalho e desenvolvimento } \\
\text { profissional. }\end{array}$ & $\mathrm{o}$ & 1,5 & 2,3 & 9,1 & 24,2 & 62,1 & o & 0,8 \\
\hline 22 & $\begin{array}{l}\text { Oferece aos empregados treinamentos } \\
\text { básicos para a realização de suas operações } \\
\text { e exercícios da função para qual foram } \\
\text { designados. }\end{array}$ & 2,3 & 1,5 & 6,8 & 18,9 & 17,4 & 50,8 & 1,5 & 0,8 \\
\hline 23 & $\begin{array}{l}\text { Mantém treinamentos regulares visando o } \\
\text { aprimoramento dos empregados nas } \\
\text { funções atuais. }\end{array}$ & 2,3 & 6,1 & 6,8 & 18,2 & 27,3 & 35,6 & 3,0 & 0,8 \\
\hline 24 & $\begin{array}{l}\text { Oferece treinamentos para todos os níveis } \\
\text { hierárquicos. }\end{array}$ & 5,3 & 8,3 & 8,3 & 16,7 & 20,4 & 35,6 & 4,5 & 0,8 \\
\hline 25 & $\begin{array}{l}\text { Oferece treinamentos aos empregados que } \\
\text { estimulam o desenvolvimento pessoal e } \\
\text { profissional além das atividades atuais. }\end{array}$ & 6,8 & 4,5 & 10,6 & 15,9 & 38,6 & 18,9 & 3,8 & 0,8 \\
\hline 26 & $\begin{array}{l}\text { Estimula os setores a se envolverem com o } \\
\text { desenvolvimento profissional. }\end{array}$ & 5,3 & 3,8 & 8,3 & 18,2 & 21,2 & 38,6 & 3,8 & $\mathrm{o}, 8$ \\
\hline 27 & $\begin{array}{l}\text { Estimula realização de cursos externos por } \\
\text { meio de concessão de bolsas ou outro } \\
\text { incentivo. }\end{array}$ & 5,3 & 5,3 & 8,3 & 18,9 & 18,2 & 37,1 & 6,1 & $\mathrm{o}, 8$ \\
\hline 28 & $\begin{array}{l}\text { Possui política transparente e consolidada } \\
\text { do benefício de bolsa de estudos. }\end{array}$ & 3,8 & 2,3 & 3,8 & 12,1 & 20,4 & 53,0 & 3,8 & 0,8 \\
\hline 29 & $\begin{array}{l}\text { Contrata aprendizes seguindo a Lei da } \\
\text { Aprendizagem. }\end{array}$ & o & o & o & 0,8 & 3,8 & 54,5 & 39,4 & 1,5 \\
\hline 30 & $\begin{array}{l}\text { Fornece treinamentos específicos para } \\
\text { estagiários e aprendizes. }\end{array}$ & 2,3 & 1,5 & 5,3 & 4,5 & 16,7 & 42,4 & 26,5 & 0,8 \\
\hline \multicolumn{2}{|r|}{ TOTAL (\%) } & 3,3 & 3,5 & 6,1 & 13,3 & 20,8 & 42,9 & 9,2 & $\mathbf{0 , 8}$ \\
\hline
\end{tabular}

Fonte: Elaborada pelos autores

Na Tabela 4, a incidência de maior concordância (5) predomina em 9 das 10 afirmativas dessa tabela, apontando para a percepção da atuação responsável da cooperativa frente às condições de trabalho e treinamento. Sobre a afirmação 25: foram registrados 38,6\%, para a opção 4; 18,9\%, para a 5; e 15,9\% para a 3, identificando reconhecimento da existência de treinamentos, porém com alguns pontos a serem melhorados e/ou esclarecidos. No que se refere a oferecer 
treinamentos para todos os níveis hierárquicos, os gerentes não manifestaram concordância total e talvez sejam necessários esclarecimentos para os ocupantes desses cargos sobre a lei da aprendizagem, uma vez que a cooperativa cumpre rigorosamente todos os procedimentos estabelecidos, conforme documentação consultada.

Tabela 5 - Atuação da cooperativa referente a demissões e aposentadorias. (Bloco A4 - Afirmações de 31 a 36

\begin{tabular}{|c|c|c|c|c|c|c|c|c|c|}
\hline № & Afirmações & o & 1 & 2 & 3 & 4 & 5 & NS & NQR \\
\hline 31 & $\begin{array}{l}\text { Segue a legislação em vigor relacionada às } \\
\text { demissões e aos processos de } \\
\text { aposentadoria. }\end{array}$ & $\mathrm{o}$ & 1,5 & $\mathrm{o}$ & 3,8 & 6,8 & 67,4 & 19,7 & 0,8 \\
\hline 32 & Possui políticas demissionais claras. & 2,3 & 3,8 & 1,5 & 10,6 & 7,6 & 45,4 & 26,5 & 2,3 \\
\hline 33 & $\begin{array}{l}\text { Dá acesso ao empregado referente ao } \\
\text { processo demissional e contribui para o } \\
\text { desenvolvimento profissional da(s) } \\
\text { pessoa(s) demitida(s). }\end{array}$ & 6,1 & 2,3 & 4,5 & 6,8 & 7,6 & 15,1 & 55,3 & 2,3 \\
\hline 34 & $\begin{array}{l}\text { Oferece programas de capacitação e } \\
\text { desenvolvimento aos empregados } \\
\text { demitidos. }\end{array}$ & 17,4 & 1,5 & 3,8 & 5,3 & 3,0 & 5,3 & 61,4 & 2,3 \\
\hline 35 & $\begin{array}{l}\text { Possui práticas para lidar com } \\
\text { empregados em processo de } \\
\text { aposentadoria. }\end{array}$ & 3,8 & 5,3 & 4,5 & 3,8 & 3,8 & 10,6 & 65,9 & 2,3 \\
\hline 36 & $\begin{array}{l}\text { Envolve familiares no processo de } \\
\text { preparação para aposentadoria de seus } \\
\text { funcionários. }\end{array}$ & 11,4 & 3,8 & 2,3 & 3,8 & 4,5 & 6,1 & 65,1 & 3,0 \\
\hline \multicolumn{2}{|r|}{ TOTAL $(\%)$} & 6,8 & 3,0 & 2,8 & 5,7 & 5,5 & 25,0 & 49,0 & $\mathbf{2 , 1}$ \\
\hline
\end{tabular}

Fonte: Elaborada pelos autores

Verifica-se, na afirmação 33, sobre acesso ao processo demissional e apoio para o desenvolvimento profissional dos demitidos, que a maioria (55,3\%) registrou NS empregado.. Quanto à afirmação 34: capacitação de empregados demitidos, também foi assinalado NS por 61,4\%. A predominância do NS se repetiu com as outras afirmações relativas à aposentadoria. Com isso constata-se que os funcionários não identificam, com clareza, os procedimentos referentes a processos demissionais e à aposentadoria. A postura em relação à aposentadoria pode-se dever ao fato de grande parte dos funcionários ser jovem, abaixo dos 40 anos de idade, ainda não preocupados com esse tipo de questão. A avaliação do conjunto das afirmações que compõem a Tabela 5 permite inferir que a grande maioria realmente desconhece as questões envolvidas, ou seja, este assunto deve ser mais divulgado e trabalhado pela cooperativa.

Nesse contexto, cabe referência a resultados de pesquisa de Souza et al. (2013), desenvolvida em operadora de plano de saúde, na qual foi levantada a RS com o PI,também por meio dos indicadores do Instituto Ethos. Apesar de ter sido possível caracterizar condições satisfatórias na qualidade de vida dos empregados, no entanto, os autores apontam algumas fragilidades, capitadas através de declarações dos entrevistados. Dentre essas fragilidades estão as posturas diante de demissões e da aposentadoria. Enquanto no caso desta pesquisa é constatado o desconhecimento ou a falta de atenção dos empregados, no caso analisado por Souza et al. (2013) é apontado maior afastamento dos indicadores de RS. Segundo os autores, no que diz respeito às demissões na operadora pesquisada, o que hoje é considerado uma falta de informação, já foi considerado pelos funcionários como estratégia de redução de custos. Quanto à aposentadoria, segundo o relatado por Souza et al. (2013), além de serem cumpridas as obrigações legais, não são percebidas outras ações da empresa para tratar as consequências da aposentadoria na vida de seus empregados. 
Com relação aos gerentes, para a afirmativa 32, sobre políticas demissionais, 33,3\% assinalaram o (zero), sendo esta a que teve maior variação entre as afirmativas, com relação às dos demais funcionários. Esse desconhecimento dos gerentes deve ser objeto de ações por parte da cooperativa.

Tabela 6 - Atuação da cooperativa referente à jornada de trabalho.

(Bloco A5 - Afirmações de 37 a 41)

\begin{tabular}{|c|c|c|c|c|c|c|c|c|c|}
\hline № & Afirmações & $\mathbf{o}$ & 1 & 2 & 3 & 4 & 5 & NS & NQR \\
\hline 37 & $\begin{array}{l}\text { Respeita a quantidade de horas de } \\
\text { trabalho dos empregados. }\end{array}$ & o & 0,8 & o & 3,8 & 9,1 & 84,8 & 0,8 & 0,8 \\
\hline 38 & $\begin{array}{l}\text { Compensa as horas extras de todos os } \\
\text { empregados, incluindo gerentes e } \\
\text { executivos de forma regular e } \\
\text { registrada. }\end{array}$ & 4,5 & 0,8 & 2,3 & 6,8 & 11,4 & 62,9 & 9,8 & 1,5 \\
\hline 39 & $\begin{array}{l}\text { Realiza um planejamento para evitar } \\
\text { horas extras frequentes. }\end{array}$ & o & 1,5 & 4,5 & 9,8 & 16,7 & 56,1 & 9,8 & 1,5 \\
\hline 40 & $\begin{array}{l}\text { Possui políticas estabelecidas e } \\
\text { divulgadas para a realização de horas } \\
\text { extras ou aplicação do banco de horas. }\end{array}$ & 4,5 & 1,5 & 4,5 & 4,5 & 12,9 & 66,7 & 4,5 & 0,8 \\
\hline 41 & $\begin{array}{l}\text { Comunica necessidade de realização de } \\
\text { horas extras com antecedência e } \\
\text { respeita a disponibilidade do }\end{array}$ & 0,8 & 2,3 & 3,8 & 7,6 & 11,4 & 68,2 & 5,3 & 0,8 \\
\hline \multicolumn{2}{|r|}{ TOTAL (\%) } & 2,0 & 1,4 & 3,0 & 6,5 & 12,3 & 67,7 & 6,1 & $\mathbf{1 , 1}$ \\
\hline
\end{tabular}

Fonte: Elaborada pelos autores

Constata-se, nas afirmações da Tabela 6, o registro do maior nível de concordância (5), com elevado percentual e alta incidência, variando de $56,1 \%$ a $84,8 \%$, indicando a atuação responsável da cooperativa em relação à jornada de trabalho e às horas extras e o reconhecimento dos funcionários desse fato. Com relação aos gerentes, na afirmativa 38, sobre compensação de horas extras de todos os empregados, houve a incidência de $33,3 \%$ assinalando 5 e o mesmo percentual para 4 . A afirmativa com maior variação entre gerentes e demais funcionários, com relação à jornada de trabalho, referiuse à afirmação 40, sobre horas extras e aplicação do banco de horas, talvez pelo fato de os gerentes não participarem de banco de horas. Em relação às demais afirmativas, os gerentes externaram visão muito próxima à dos demais funcionários com pouca variação nas outras afirmativas. Esperar-se-ia, no entanto, que os gerentes expressassem a postura da empresa e não as ações referentes às suas próprias condições. 
Tabela 7 - Posição da cooperativa referente a ações de prevenção e de melhoria das condições do trabalhador e da família (Bloco A6 - Afirmações de 42 a 56)

\begin{tabular}{|c|c|c|c|c|c|c|c|c|c|}
\hline № & Afirmações & $\mathbf{o}$ & $\mathbf{1}$ & 2 & 3 & 4 & 5 & NS & NQR \\
\hline 42 & $\begin{array}{l}\text { Atende às exigências das Normas Regulatórias } \\
\text { ou tem um plano de ação para garantir o seu } \\
\text { cumprimento, especialmente no que se refere a } \\
\text { emergência e riscos de incêndio. }\end{array}$ & o & o & o & 3,8 & 14,4 & 78,8 & 2,3 & 0,8 \\
\hline 43 & $\begin{array}{l}\text { Indica um responsável para gerenciar ou } \\
\text { mantém um comitê de prevenção de acidentes } \\
\text { atendendo às exigências das normas } \\
\text { regulamentadoras. }\end{array}$ & $\mathrm{o}, 8$ & o & o & 3,0 & 7,6 & 85,6 & 2,3 & 0,8 \\
\hline 44 & $\begin{array}{l}\text { Possui iniciativas de combate ao estresse dos } \\
\text { empregados. }\end{array}$ & 26,5 & 9,1 & 7,6 & 9,1 & 9,8 & 17,4 & 17,4 & 3,0 \\
\hline 45 & $\begin{array}{l}\text { Promove exercícios físicos em horário de } \\
\text { trabalho. }\end{array}$ & 84,1 & 1,5 & 1,5 & o & 1,5 & 5,3 & 3,8 & 2,3 \\
\hline 46 & $\begin{array}{l}\text { Mantém programas de combate ao estresse, } \\
\text { orientação alimentar e nutricional, equilíbrio } \\
\text { trabalho-família, incluindo o respeito e limites } \\
\text { com relação ao trabalho remoto (telefonemas e } \\
\text { e-mails fora do horário de trabalho). }\end{array}$ & 31,1 & 9,09 & 6,8 & 10,6 & 9,1 & 13,6 & 15,1 & 4,5 \\
\hline 47 & $\begin{array}{l}\text { Oferece programa de prevenção e tratamento } \\
\text { para dependência de álcool e drogas. }\end{array}$ & 39,4 & 5,3 & 5,3 & 3,8 & 1,5 & 6,1 & 36,4 & 2,3 \\
\hline 48 & $\begin{array}{l}\text { Realiza pesquisa visando medir o nível de } \\
\text { satisfação dos empregados. }\end{array}$ & 32,6 & 7,58 & 9,8 & 8,3 & 6,8 & 15,1 & 17,4 & 2,3 \\
\hline 49 & $\begin{array}{l}\text { Desenvolve programas que têm como objetivo } \\
\text { melhorias no ambiente de trabalho, que } \\
\text { beneficiam os empregados e prestadores de } \\
\text { serviços. }\end{array}$ & 17,4 & 6,82 & 15,1 & 13,6 & 8,3 & 18,9 & 18,9 & $\mathrm{o}, 8$ \\
\hline 50 & $\begin{array}{l}\text { É reconhecida por suas práticas em qualidade } \\
\text { de vida e por uma jornada de trabalho justa. }\end{array}$ & 2,3 & 3,03 & 5,3 & 13,6 & 15,1 & 53,0 & 6,1 & 1,5 \\
\hline 51 & $\begin{array}{l}\text { Possui programas e canais para que os temas } \\
\text { da qualidade de vida cheguem à família dos } \\
\text { empregados. }\end{array}$ & 25,0 & 3,8 & 9,8 & 9,1 & 9,8 & 19,7 & 18,9 & 3,8 \\
\hline $5^{2}$ & $\begin{array}{l}\text { Organiza campanhas que visam a melhoria da } \\
\text { qualidade de vida não somente dos } \\
\text { empregados e de seus familiares, mas da } \\
\text { sociedade em geral, seja como patrocinador, } \\
\text { seja como agente ativo de campanhas a } \\
\text { respeito. }\end{array}$ & 5,3 & 5,3 & 6,1 & 17,4 & 18,2 & 31,1 & 14,4 & 2,3 \\
\hline 53 & $\begin{array}{l}\text { Possui normas para combater situações de } \\
\text { assédio moral ou sexual, as quais são } \\
\text { divulgadas e devidamente amparadas por } \\
\text { estrutura formal e neutra de denúncia e } \\
\text { apuração de fatos. }\end{array}$ & 14,4 & 8,3 & 6,8 & 7,6 & 9,8 & 31,1 & 19,7 & 2,3 \\
\hline 54 & $\begin{array}{l}\text { As práticas da cooperativa servem } \\
\text { frequentemente de referência para outras } \\
\text { empresas. }\end{array}$ & $\mathrm{o}, 8$ & 4,5 & 1,5 & 12,9 & 15,9 & 43,2 & 18,9 & 2,3 \\
\hline 55 & $\begin{array}{l}\text { Oferece canal de fácil acesso com mecanismos } \\
\text { para receber e encaminhar sugestões, opiniões } \\
\text { e reclamações relativas às condições de } \\
\text { trabalho. }\end{array}$ & 6,8 & 4,5 & 6,8 & 13,6 & 12,1 & 43,9 & 10,6 & 1,5 \\
\hline 56 & $\begin{array}{l}\text { Desenvolve práticas para envolver os } \\
\text { empregados na solução dos problemas da } \\
\text { empresa. }\end{array}$ & 11,4 & 3,8 & 8,3 & 12,9 & 16,7 & 28,8 & 16,7 & 1,5 \\
\hline \multicolumn{2}{|r|}{ TOTAL (\%) } & 19,8 & 4,8 & 6,1 & 9,3 & 10,4 & 32,8 & 14,6 & $2, \mathbf{1}$ \\
\hline
\end{tabular}

Fonte: Elaborada pelos autores. 
É grande a variação das posições dos funcionários referentes a ações de prevenção e à melhoria das condições do trabalhador e da família. As ações gerais de prevenção - afirmações 42 e 43 - são reconhecidas com alto percentual: $78 \%, 79 \%$ e 85,6\%. No entanto, é diferente a posição em relação às condições do trabalhador. Em relação à afirmação 44 - iniciativas de combate ao estresse dos empregados, $26,5 \%$ assinalaram o (zero). Também para a afirmativa 45 - exercícios físicos em horário de trabalho - 84,1\% - assinalaram o (zero). Essa alta incidência põe em evidência pontos a serem discutidos e melhorados pela cooperativa em relação a seu PI. Resultados de algumas afirmativas indicam que a questão de combate ao estresse deve ser contemplada pela cooperativa, pois grande parte dos funcionários não identifica programas de combate ao estresse e relativos ao trabalho remoto, fora do horário. De fato, a consulta aos programas da empresa não indica a existência desse programa, valorizado como indicador de RS e, portanto, a ser considerado pela cooperativa. Em relação à afirmativa 48, sobre nível de satisfação dos empregados, 32,6\% dos funcionários assinalaram o (zero) e $17,4 \%$ NS, porcentagens consideráveis; apenas $15,1 \%$ indicaram a opção 5. A cooperativa deverá analisar essa questão de nível de conhecimento ou satisfação, pois a maioria não identifica ou não dispõe de informações sobre o assunto. Nas afirmações referentes a ações de prevenção e de melhoria das condições do trabalhador e família, a maior incidência, para o conjunto do Bloco, foi da opção 5, com 32,8\%. No entanto, algumas afirmativas, com indicação o (zero) ou NS, tais como - promoção de exercícios físicos em horário de trabalho, manutenção de programas de combate ao estresse, orientação alimentar e nutricional, equilíbrio trabalho/família, incluindo respeito e limites com relação ao trabalho remoto, devem ser avaliadas e trabalhadas pela cooperativa.

Cruz et al. (2012) ao discutirem as relações entre RSI e comprometimento organizacional destacam que a RS da empresa com o PI estimula uma maior produtividade, compromisso e motivação, como também resulta em menor rotatividade de funcionários. Esta observação deve ser considerada tendo em vista tanto o bem estar dos empregados quando o melhor desempenho da empresa, seja ou não uma organização cooperativa.

Com relação aos gerentes, foi constatada grande variação entre o posicionamento deles e dos demais funcionários, no que diz respeito às iniciativas de combate ao estresse. Na afirmativa 50 houve uma variação das respostas dos funcionários e dos gerentes: os primeiros, em sua maioria $53 \%$ - assinalaram 5 e os gerentes apenas $22,2 \%$, ou seja, é provável que a jornada de trabalho dos gerentes seja maior. No entanto espera-se, dos que exercem função de gestão, a percepção das ocorrências para o conjunto dos empregados.

O que foi registrado na comparação da atuação da Cooperativa com outras Instituições Financeiras está apresentado na Tabela 8. 
Tabela 8 - Afirmações referentes à comparação desta cooperativa com outras instituições financeiras - (Bloco A7 - Afirmações de 57 a 64)

\begin{tabular}{|c|c|c|c|c|c|c|c|c|c|}
\hline № & Afirmações & $\mathbf{o}$ & 1 & 2 & 3 & 4 & 5 & NS & NQR \\
\hline 57 & $\begin{array}{l}\text { A relação com os sindicatos é a mesma na } \\
\text { cooperativa e em outras instituições financeiras. } \\
\text { As demais instituições financeiras são }\end{array}$ & 15,1 & 3,0 & 3,0 & 8,3 & 4,5 & 15,9 & 48,5 & 1,5 \\
\hline 58 & $\begin{array}{l}\text { cooperativas reconhecidas pelas suas práticas } \\
\text { de remuneração. }\end{array}$ & 5,3 & 0,8 & 6,8 & 9,8 & 15,1 & 23,5 & 35,6 & 3,1 \\
\hline 59 & $\begin{array}{l}\text { As demais instituições financeiras não } \\
\text { cooperativas possuem benefícios como planos } \\
\text { de saúde, odontológico, bolsas de estudo e } \\
\text { lazer. }\end{array}$ & 0,8 & 0,8 & 4,5 & 9,8 & 12,9 & 34,1 & 34,1 & 3,1 \\
\hline 60 & $\begin{array}{l}\text { As demais instituições financeiras não } \\
\text { cooperativas possuem programas de resultados } \\
\text { ou de bonificação negociados entre empregados } \\
\text { e sindicatos. }\end{array}$ & 0,8 & 2,3 & 2,3 & 9,1 & 11,4 & 28,8 & 43,9 & 1,5 \\
\hline 61 & $\begin{array}{l}\text { As cooperativas de crédito possuem as mesmas } \\
\text { condições de trabalho em comparação com as } \\
\text { demais instituições financeiras não } \\
\text { cooperativas. }\end{array}$ & 11,4 & 6,8 & 4,5 & 11,4 & 11,4 & 20,4 & 32,6 & 1,5 \\
\hline 62 & $\begin{array}{l}\text { As instituições financeiras não cooperativas } \\
\text { possuem os mesmos critérios de avaliação de } \\
\text { desempenho e remuneração adotados por esta } \\
\text { cooperativa. }\end{array}$ & 17,4 & 3,0 & 5,3 & 6,8 & 4,5 & 5,3 & 56,1 & 1,5 \\
\hline 63 & $\begin{array}{l}\text { Esta cooperativa de crédito atrai profissionais e } \\
\text { é procurada pelas suas condições de trabalho e } \\
\text { desenvolvimento profissional. }\end{array}$ & o & 3,0 & 3,8 & 12,1 & 14,4 & 54,5 & 10,6 & 1,5 \\
\hline 64 & $\begin{array}{l}\text { As demais instituições financeiras não } \\
\text { cooperativas da mesma forma que esta } \\
\text { cooperativa atraem profissionais e são } \\
\text { procuradas pelas suas condições de trabalho e } \\
\text { desenvolvimento profissional. }\end{array}$ & 3,1 & 3,8 & 9,1 & 14,4 & 14,4 & 16,7 & 37,1 & 1,5 \\
\hline \multicolumn{2}{|c|}{ TOTAL (\%) } & 6,7 & 2,9 & 4,9 & 10,2 & 11,1 & 24,9 & 37,3 & 1,9 \\
\hline
\end{tabular}

Fonte: Elaborada pelos autores

Para a afirmação 57, sobre a relação com os sindicatos, na cooperativa e em outras instituições financeiras, foi alto o percentual, $48,5 \%$, dos que assinalaram NS. Dois extremos foram ainda indicados: $15,1 \%$ marcaram o (zero) e 15,9\% assinalaram 5. Para a afirmativa 59, sobre a presença de benefícios (planos, bolsas de estudos e lazer), em outras empresas e na cooperativa, houve a mesma porcentagem para as opções 5 e NS - 34,1\%, indicando a pouca divulgação junto ao PI desse tipo de ação, existente na cooperativa, conforme constatado em documentação sobre seus programas. Com relação às instituições financeiras não cooperativas possuírem os mesmos critérios de avaliação de desempenho e remuneração adotados pela cooperativa, a predominância, 56,1\%, foi de NS e $17,4 \%$ indicaram o (zero). Portanto, a maioria não possui conhecimento dos critérios de avaliação de desempenho em relação às demais instituições financeiras, o que requer que a cooperativa demonstre as condições diferenciadas que pratica. Nas afirmações referentes à comparação da cooperativa com outras instituições financeiras, a prevalência foi na opção NS, com $37,3 \%$, sendo mais evidente nas afirmativas relativas a: $\mathbf{1}^{\mathbf{0}}$ ) "as instituições financeiras não cooperativas possuem os mesmos critérios de avaliação de desempenho e remuneração adotados por esta cooperativa" com $56,1 \% ; 2^{\circ}$ ) "a relação com os sindicatos é a mesma na cooperativa e em outras instituições financeiras", com 48,5\%; e $3^{-0}$ ) "as demais instituições financeiras não cooperativas possuem programas de resultados ou de bonificação negociados entre empregados e sindicatos", com $43,9 \%$, identificando, assim, que a Cooperativa necessita de demonstrar seu diferencial também para 
o PI, se de fato, objetiva desenvolver procedimentos que a distingam das demais instituições financeiras, no que diz respeito a ações de RS.

De modo geral, a avaliação dos resultados dos 7 Blocos indica que a maior parte dos funcionários, incluídos os gerentes, identifica a prática de RS para com eles, na condição de PI. No entanto, na mesma direção dos resultados obtidos por Noriler e Machado (2008), transparece a necessidade de maior atuação da cooperativa, explicitando suas ações, objetivando maior articulação do PI entre os próprios funcionários e para com a organização.

Os resultados da investigação devem contribuir para que a cooperativa esteja ciente de que o sentimento de segurança, por parte dos funcionários, quer no ambiente do trabalho, quer no familiar, contribuem positivamente para a execução de suas atividades, conforme o identificado por Piccinini et. al. (2003).

\subsection{1. - Avaliação das divergências entre as variáveis/categorias sexo, idade, instrução e posição funcional (gerentes e ocupantes de outros cargos)}

Para a verificação de diferenças entre as opiniões médias dos respondentes por categoria (sexo, idade, instrução, gestores e funcionários), realizou-se uma Análise de Variância (ANOVA) com auxílio do Software Minitab ${ }^{\oplus}$ v.17. A Tabela 9 apresenta blocos e questões com divergências de respostas para níveis de significância $\alpha=5 \%$ e $\alpha=10 \%$.

Tabela 9 - Questões e respectivos blocos que apresentam diferenças médias das respostas em função das categorias

\begin{tabular}{ccccc}
\hline & $\begin{array}{r}\alpha=0,05 \\
\text { Blocos }\end{array}$ & Questões & $\begin{array}{c}\alpha=0,10 \\
\text { Blocos }\end{array}$ & Questões \\
\hline \multirow{2}{*}{ Sexo } & 2 & 20 & 2 & 18 \\
& 5 & 39 & 4 & 35 \\
Idade & 6 & 48 & 7 & 64 \\
& 4 & 33 & 2 & 12,18 \\
Nível de & 6 & $46,51,54$ & 3 & 21 \\
Instrução & 6 & 51 & 4 & 36 \\
& & & 6 & 25,26 \\
Gestores e & 4 & 35 & 2 & 47 \\
Funcionários & 5 & 39 & 5 & 38 \\
& 6 & 48 & 6 & 56 \\
& 7 & 62,63 & & \\
\hline
\end{tabular}

Fonte: Elaborada pelos autores

Dos sete blocos de afirmações referentes à atuação da cooperativa em relação a: 1. condições e contratos de trabalho e relações sindicais; 2. obrigações trabalhistas, salariais e benefícios; 3 . condições de trabalho e treinamento; 4. demissões e aposentadorias; 5 . jornada de trabalho; 6. ações de prevenção e de melhoria das condições do trabalhador e família; 7. comparação da cooperativa com outras instituições financeiras - apenas as afirmações do bloco 1 não apresentaram divergência em relação a nenhuma das variáveis: sexo, idade, instrução ou posição funcional (gerentes e ocupantes de outros cargos).

Conforme o apresentado no Quadro 4, os dados extraídos do software Minitab 17, apontam para diferença significativa entre médias (homens e mulheres) em questões abrangidas pelos Blocos $2,4,5,6$, e 7 . 
Quadro 4 Diferenças em relação a sexo: níveis de significância o,05 e o,10

\begin{tabular}{|c|c|c|}
\hline $\begin{array}{l}\text { BLO } \\
\text { COS }\end{array}$ & AFIRMAÇÕES & EXPLICAÇÃO/AVALIAÇÃO \\
\hline \multicolumn{3}{|c|}{ Nível de significância o,o5 } \\
\hline 2 & $\begin{array}{l}20 \text { "Oferece benefícios que abrangem os } \\
\text { familiares, como participação em plano } \\
\text { odontológico, de saúde, bolsas de estudo, } \\
\text { opções de lazer etc." }\end{array}$ & $\begin{array}{l}\text { Há variação moderada entre sexos; os } \\
\text { homens identificam maiores benefícios que } \\
\text { abrangem os familiares em nível de } \\
\text { concordância mais do que as mulheres. }\end{array}$ \\
\hline 5 & $\begin{array}{l}39 \text { "Realiza um planejamento para evitar } \\
\text { horas extras frequentes". }\end{array}$ & $\begin{array}{l}\text { Mulheres e homens identificaram a presença } \\
\text { de planejamento; os homens, porém com } \\
\text { menor nível de concordância. }\end{array}$ \\
\hline 6 & $\begin{array}{l}48 \text { "Realiza pesquisas visando medir o nível } \\
\text { de satisfação dos empregados" }\end{array}$ & $\begin{array}{l}\text { Grande parte dos homens registrou NS e } \\
\text { NQR e grande parte das mulheres, assinalou } \\
5 \text { - maior nível de concordância. }\end{array}$ \\
\hline \multicolumn{3}{|c|}{ Nível de significância o,10 } \\
\hline 2 & $\begin{array}{l}18 \text { "É flexível frente às necessidades pessoais } \\
\text { dos empregados no planejamento do } \\
\text { trabalho". }\end{array}$ & $\begin{array}{l}\text { Há uma variação sugestiva entre sexos sobre } \\
\text { a resposta para essa questão, em relação à } \\
\text { qual os homens identificam maior } \\
\text { flexibilidade. }\end{array}$ \\
\hline 4 & $\begin{array}{l}35 \text { "Possui práticas para lidar com } \\
\text { empregados em processo de aposentadoria" }\end{array}$ & $\begin{array}{l}\text { Os homens e mulheres identificaram as } \\
\text { práticas, porém as mulheres em menor } \\
\text { freqüência. }\end{array}$ \\
\hline 7 & $\begin{array}{l}64 \text { "As demais instituições financeiras não } \\
\text { cooperativas da mesma forma que esta } \\
\text { cooperativa atraem profissionais e são } \\
\text { procuradas pelas suas condições de } \\
\text { trabalho e desenvolvimento profissional". }\end{array}$ & $\begin{array}{l}\text { Nessa afirmação as mulheres foram mais } \\
\text { enfáticas no que diz respeito à maior atração } \\
\text { pelas melhores condições por parte das } \\
\text { cooperativas. }\end{array}$ \\
\hline
\end{tabular}

Fonte: Elaborado pelos autores

Diferença significativa foram observadas entre médias (faixas etárias) com nível de significância igual à $5 \%$ - valor-p < 0,05, para questões 33 (Bloco 2), 46, 51 e 54 (Bloco 6) e com nível de significância igual à 10\% - valor-p < o,10, para as Questões 12 e 18 (Bloco 2), 21 (Bloco 3 ) e 36 (Bloco 4), conforme o apresentado do Quadro 5. 
Quadro 5 Diferenças em relação a faixas etárias: níveis de significância o,o5 e o,10

\begin{tabular}{|c|c|c|}
\hline $\begin{array}{l}\text { BLO } \\
\text { COS }\end{array}$ & AFIRMAÇÕES & EXPLICAÇÃO/AVALIAÇÃO \\
\hline \multicolumn{3}{|c|}{ Nível de significância o,o5 } \\
\hline 4 & $\begin{array}{l}33 \text { "Dá acesso ao empregado referente ao } \\
\text { processo demissional e contribui para o } \\
\text { desenvolvimento profissional da(s) pessoa(s) } \\
\text { demitida(s)". }\end{array}$ & $\begin{array}{l}\text { Identifica-se que os jovens têm menor } \\
\text { preocupação com esse tema. }\end{array}$ \\
\hline 6 & $\begin{array}{l}46 \text { "Mantém programas de combate ao estresse, } \\
\text { orientação alimentar e nutricional, equilíbrio } \\
\text { trabalho/família, incluindo respeito e limites } \\
\text { com relação ao trabalho remoto, como por } \\
\text { exemplo, telefonemas e e-mails fora do horário } \\
\text { de trabalho". } \\
51 \text { "Possui programas e canais para que os temas } \\
\text { da qualidade de vida cheguem à família dos } \\
\text { empregados". } \\
54 \text { "As práticas da cooperativa servem } \\
\text { frequentemente de referência para outras } \\
\text { empresas". }\end{array}$ & $\begin{array}{l}\text { Geralmente os jovens são solteiros e têm menor } \\
\text { preocupação com essa questão. } \\
\text { Grande parte dos jovens não soube responder } \\
\text { (NS) enquanto os de maior idade identificaram } \\
\text { essa referência. }\end{array}$ \\
\hline \multicolumn{3}{|c|}{ Nível de significância o,10 } \\
\hline 2 & $\begin{array}{l}12 \text { "Possui política de remuneração" } \\
18 \text { "É flexível frente às necessidades pessoais dos } \\
\text { empregados no planejamento do trabalho". }\end{array}$ & $\begin{array}{l}\text { Há uma variação sugestiva entre jovens e os com } \\
\text { maior idade, sendo que os jovens se preocupam } \\
\text { menos com a temática. } \\
\text { Como geralmente os jovens não possuem filhos, } \\
\text { prendem-se menos a questões do tempo no } \\
\text { trabalho. }\end{array}$ \\
\hline 3 & $\begin{array}{l}21 \text { "Atrai profissionais e é procurada pelas suas } \\
\text { condições de trabalho e desenvolvimento } \\
\text { profissional" }\end{array}$ & $\begin{array}{l}\text { Os funcionários com maior idade identificam-se } \\
\text { mais com essa temática relacionada a condições } \\
\text { de trabalho. }\end{array}$ \\
\hline 4 & $\begin{array}{l}36 \text { "Envolve familiares no processo de } \\
\text { preparação para a aposentadoria de seus } \\
\text { funcionários" }\end{array}$ & $\begin{array}{l}\text { Grande parte dos jovens não se preocupa com } \\
\text { aposentadoria e é menor o envolvimento dos } \\
\text { familiares com a temática. }\end{array}$ \\
\hline
\end{tabular}

Fonte: Elaborado pelos autores

Diferença significativa entre médias (nível instrução) com nível de significância igual a 5\% valor-p < o,05 é encontrado na questão Q51 (Bloco 6). Com nível de significância igual a 10\% - valor-p $<0,10$ inclui as questões 25 e 26 (Bloco 3) e 47 (Bloco 6).

Em relação ao nível de instrução: níveis de significância o,05 e o,10.

\begin{tabular}{|c|c|c|}
\hline \multicolumn{1}{|c|}{ BLOCOS } & \multicolumn{1}{|c|}{ EXPLICAÇÃO/AVALIAÇÃO } \\
\hline \multicolumn{2}{|c|}{ Quadro 6 Diferenças Nível de significância o,o5 } \\
\hline $\mathbf{6}$ & $\begin{array}{l}51 \text { "Possui programas e canais para que os temas da qualidade } \\
\text { de vida cheguem à família dos empregados". }\end{array}$ & $\begin{array}{l}\text { Observa-se uma significância moderada entre os funcionários } \\
\text { com nivel de escolaridade maior e menor, sendo que os que } \\
\text { têm nível maior se preocupam mais com o tema. }\end{array}$ \\
\hline $\mathbf{3}$ & $\begin{array}{l}25 \text { "Oferece treinamentos aos empregados que estimulam o } \\
\text { desenvolvimento pessoal e profissional além das atividades } \\
\text { atuais" } \\
26 \text { "Estimula os setores a se envolverem com o } \\
\text { desenvolvimento profissional” }\end{array}$ & $\begin{array}{l}\text { Quem possui menor nível de instrução não se preocupa com } \\
\text { a temática treinamento. }\end{array}$ \\
\hline $\mathbf{6}$ & $\begin{array}{l}\text { 47 "Oferece programa de prevenção e tratamento para } \\
\text { dependência de álcool e drogas" }\end{array}$ & $\begin{array}{l}\text { A afirmação está mais ligada à preocupação dos funcionários } \\
\text { mais jovens. }\end{array}$ \\
\hline
\end{tabular}


Foi constatada diferença significativa entre médias (gestores e funcionários) com nível de significância igual a 5\%- valor-p < 0,05 para as questões 13 (Bloco 2), 35 (Bloco 4), 39 (Bloco 5), 48 (Bloco 6), 62 e 63 (Bloco 7) e com nível de significância igual a 10\% - valor-p < 0,10, as questões 16 (Bloco 2), 38 (Bloco 5) e 56 (Bloco 6), conforme o apresentado do Quadro 7.

Quadro 7 Diferenças em relação a gestores e funcionários: níveis de significância o,05 e 0,10

\begin{tabular}{|c|c|c|}
\hline $\begin{array}{l}\text { BLO } \\
\text { COS }\end{array}$ & AFIRMAÇÕES & EXPLICAÇÃO/AVALIAÇÃO \\
\hline \multicolumn{3}{|c|}{ Nível de significância o,o5 } \\
\hline 2 & $\begin{array}{l}13 \text { "Possui procedimentos formais e claros de } \\
\text { promoção e aumento salarial". }\end{array}$ & $\begin{array}{l}\text { Grande parte dos gerentes assinalou o (zero), } \\
\text { afirmando que a empresa não possui procedimentos } \\
\text { formais de promoção salarial. Estranha-se essa } \\
\text { afirmativa, pois os gerentes são responsáveis por } \\
\text { promoção e aumento salarial dos funcionários. }\end{array}$ \\
\hline 4 & $\begin{array}{l}35 \text { "Possui práticas para lidar com empregados em } \\
\text { processo de aposentadoria" }\end{array}$ & $\begin{array}{l}\text { Grande parte dos funcionários informou } 5 \text {, porém os } \\
\text { gerentes assinalaram, com igual percentual, o (zero) e } \\
\text { NS. }\end{array}$ \\
\hline 5 & $\begin{array}{l}39 \text { "Realiza um planejamento para evitar horas extras } \\
\text { frequentes" }\end{array}$ & $\begin{array}{l}\text { Os funcionários, em grande parte, assinalaram } 5 \text { e os } \\
\text { gerentes pulverizaram suas respostas em } 1,3,4 \text { e } 5 \text {. } \\
\text { Nesse caso, a marcação de horas extras é diferenciada } \\
\text { entre funcionários e gerentes: os funcionários marcam } \\
\text { o ponto eletrônico de controle de horas e os gerentes } \\
\text { não. A questão } 39 \text { apresentou também variância em } \\
\text { relação a sexo, chamando a atenção para que seja } \\
\text { objeto de discussão. }\end{array}$ \\
\hline 6 & $\begin{array}{l}48 \text { Realiza pesquisas visando medir o nível de } \\
\text { satisfação dos empregados". }\end{array}$ & $\begin{array}{l}\text { A maior frequência para os funcionários está em o } \\
\text { (zero), significando a não percepção de realização de } \\
\text { pesquisa. Os gerentes também assinalaram o (zero), } \\
\text { porém com menor porcentagem. Este é um ponto } \\
\text { sobre o qual a cooperativa deverá atuar para melhoria } \\
\text { da satisfação dos funcionários. Foi registrada variância } \\
\text { entre gestores e funcionários e também entre homens e } \\
\text { mulheres. }\end{array}$ \\
\hline 7 & $\begin{array}{l}62 \text { "As instituições financeiras não cooperativas } \\
\text { possuem os mesmos critérios de avaliação de } \\
\text { desempenho e remuneração adotados por esta } \\
\text { cooperativa" } \\
63 \text { "Esta cooperativa de crédito atrai profissionais e é } \\
\text { procurada pelas suas condições de trabalho e } \\
\text { desenvolvimento profissional". }\end{array}$ & $\begin{array}{l}\text { Grande parte dos funcionários assinalou NS; já os } \\
\text { gerentes assinaram o (zero), o que indica não } \\
\text { identificarem os mesmos critérios de avaliação. } \\
\text { Tanto os funcionários quantos os gerentes assinalaram } \\
\text { 5, demonstrando que a cooperativa valoriza os } \\
\text { funcionários. }\end{array}$ \\
\hline \multicolumn{3}{|c|}{ Nível de significância o,10 } \\
\hline 2 & $\begin{array}{l}16 \text { "Avalia o desempenho dos empregados de maneira } \\
\text { sistemática, pelo menos uma vez ao ano". }\end{array}$ & $\begin{array}{l}\text { Funcionários e gerentes, em sua grande parte, } \\
\text { assinalaram 5. Os gerentes, no entanto, pulverizaram } \\
\text { indicações entre as alternativas, identificando que a } \\
\text { cooperativa realiza avaliação, porém não da maneira } \\
\text { que gostariam. Este posicionamento chama a atenção } \\
\text { para a necessidade de avaliação dessa questão, } \\
\text { envolvendo a direção e o conjunto de funcionários, } \\
\text { independentemente do cargo que ocupam. }\end{array}$ \\
\hline 5 & $\begin{array}{l}38 \text { "Compensa as horas extras de todos os } \\
\text { empregados, incluindo gerentes e executivos de forma } \\
\text { regular e registrada". }\end{array}$ & $\begin{array}{l}\text { Grande parte dos funcionários assinalou } 5 \text { e os gerentes } \\
\text { se distribuíram pelas indicações } 4 \text { e } 5 \text {, provavelmente } \\
\text { devido à marcação do ponto ser diferente entre } \\
\text { funcionários e gerentes }\end{array}$ \\
\hline 6 & $\begin{array}{l}56 \text { "Desenvolve práticas para envolver os empregados } \\
\text { na solução dos problemas da empresa". }\end{array}$ & $\begin{array}{l}\text { Tanto entre os funcionários como entre gerentes as } \\
\text { indicações ficaram pulverizadas, porém grande parte } \\
\text { dos funcionários assinalou } 5 \text { e os gerentes } 2 \text {, o que } \\
\text { sugere discussão, análise e avaliação, tendo em vista a } \\
\text { relevância da democratização das decisões. }\end{array}$ \\
\hline
\end{tabular}

Fonte: Elaborado pelos autores 
O emprego de técnicas quantitativas (ANOVA) no tratamento dos dados levantados pelos questionários e a análise de resultados comparativos entre as questões indicam que houve pouca variância entre sexos, idades, graus de instrução e entre gerentes e funcionários, chegando à média de 3,5 do total de 64 questões.

Alguns resultados chamaram a atenção pela discrepância de avaliação/percepção, sobretudo em relação à variação de faixa etária, mas também ao sexo ou ao grau de instrução. Assim sendo, pode-se inferir que as afirmações não foram avaliadas segundo a perspectiva da empresa como um todo, voltadas para o conjunto de todos os funcionários, mas considerando apenas a perspectiva da faixa etária, ou ainda do sexo ou do grau de instrução em que se enquadrava o respondente. Esse seria um espaço para a empresa atuar, contribuindo para a formação de cidadãos.

Diante da avaliação das respostas dos gerentes e diante dos resultados obtidos pela investigação, avalia-se importante a discussão e a avaliação da percepção deles, considerando os princípios, os compromissos e os programas desenvolvidos pela cooperativa.

\section{Conclusões}

Conseguiu-se identificar e avaliar as principais ações de responsabilidade social praticadas pela cooperativa com seu PI, utilizando, com modificações, os Indicadores Ethos de Responsabilidade Social Empresarial específico para o PI.

Os resultados alcançados indicam que a maior parte dos funcionários compreende e enxerga a responsabilidade social que a cooperativa pratica em relação a eles e à maioria dos aspectos investigados. Foram, porém, identificados alguns pontos, alguns deles nos quais a cooperativa terá que atuar para melhor entendimento e engajamento de seus empregados.

Os investimentos feitos na formação profissional dos funcionários, somados aos benefícios extensivos aos familiares, representam postura no sentido de motivar o desenvolvimento e o bom desempenho dos profissionais e o retorno desses investimentos pode ser facilmente vinculado ao comprometimento com as atividades e os objetivos da cooperativa. Acredita-se que quanto mais confortáveis e seguros os funcionários se sintam, em relação à sua qualificação profissional, ao seu ambiente de trabalho e na vivência familiar, de melhor forma tenderão a executar suas atividades.

Foram identificadas evidências de que a cooperativa atua de forma responsável em relação a todos os seus funcionários, desenvolvendo boas práticas de gestão de pessoas e, muitas delas, em consonância com as práticas de RS, de acordo com os Indicadores Ethos, os quais estão próximos dos sete princípios cooperativistas.

O questionário utilizado, adaptado, em seis de seus blocos, do elaborado pelo Instituto Ethos, mostrou-se eficiente e eficaz. Cabe ressaltar que as informações levantadas e os resultados obtidos referendaram a relevância das adaptações, sobretudo no que diz respeito à apresentação de oito alternativas, em lugar de apenas as opções SIM ou NÃO, adotadas pelo questionário original. A proposta de um leque de oito opções possibilitou apreender não apenas o conhecimento dos funcionários sobre a presença de ações de RS, mas, de forma refinada, o grau desse conhecimento ou mesmo da presença das referidas ações. Assim sendo, o questionário aplicado, na investigação que fundamenta o presente artigo, se apresenta como um produto dela, podendo ser utilizado em outras pesquisas, com objetivos semelhantes.

A abordagem qualitativa e quantitativa, no tratamento e na avaliação de dados e informações, possibilitou ampliação e aprofundamento dos conhecimentos sobre RS para com o PI de cooperativas. 
Pretende-se que os resultados obtidos sirvam de reflexão e utilização pelos setores da cooperativa, diretamente envolvidos, tais como o departamento de Recursos Humanos, a fim de que possam aperfeiçoar práticas realizadas em seu cotidiano ou projetadas para o médio e o longo prazos. Pretende-se, também que, a partir do relato da metodologia utilizada na condução da investigação e dos resultados obtidos, a pesquisa possa ser replicada em outras unidades da cooperativa objeto da investigação e mesmo em outras empresas, cooperativas ou não, do mesmo ou de outros ramos. Por se tratar de avaliação com o PI os procedimentos podem ser objeto de replicação, com nenhuma ou com poucas adaptações.

\section{Referências}

BA, S.A.C.; MARTINS, K.C.; Gestão de responsabilidade social em uma cooperativa médica: um estudo de caso. Semead, 13. Set/2010. USP. São Paulo.

BERTO, R. M. V. S.; NAKANO, D. N. A Produção Científica nos Anais do Encontro Nacional de Engenharia de Produção: um levantamento de métodos e tipos de pesquisa. Produção, vol.9, no 2, p.65-76, 2000.

BERTO, R. M. V. S.; NAKANO, D. N. Revisitando a produção científica nos Anais do Encontro Nacional de Engenharia de Produção. Production Journal, vol.24, n.1, p.225-232, 2014.

BIALOSKORSKI NETO, S. Cooperativas: Economia, Crescimento e Estrutura de Capital. 1998. 202 p. Tese (Doutorado em Ciência Econômica Aplicada) - Escola Superior de Agricultura "Luiz de Queiroz", Universidade de São Paulo, Piracicaba, 1998.

BUSSLER, N. R. C.; SAUSEN, J. F. C. L.; BAGGIO, D.K.; FROEMMING, L. M. S.; FERNANDEZ, S.B.V. Responsabilidade social e a governança corporativa: perspectivas de gestão socioambiental nas organizações. Revista de Gestão e Organizações Cooperativas - RGC, Santa Maria, v.4, n.8, p. 91-108, 2oㅡ. Sem. 2017. DOI: dx.doi.org/10.5902/2359043227199.

CACCIA, C.Z.; ZARELLI, F.M.; GIMENES, F.M.P.A. A prática da responsabilidade social das cooperativas agroindustriais paranaenses Coamo e Cocamar. Revista Ciências Empresariais. UNIPAR, Umuarama, v. 9, n. 1 e 2, p. 69-90, jan./ dez. 2008.

CANÇADO, A. C.; SILVA JÚNIOR, J. T.; RIGO, A. S, Princípio da Preocupação com a Comunidade ou Responsabilidade Social para Cooperativas? Uma abordagem baseada na Teoria da Dádiva. In: ENCONTRO LATINO AMERICANO DE PESQUISADORES DA ACI, 20o8. Anais...Ribeirão Preto, 2008.

CANÇADO, A. C.; RIGO, A. S.; PEREIRA J. R.; GONTIJO M. C. H. Movimento e Princípios Cooperativistas: Evolução e Reflexões para Novos Estudos. In CANÇADO, A. C.; F. G. TENÓRIO ; J. T. SILVA JR (Orgs.). Gestão Social: aspectos teóricos e aplicações. Ijuí: UNIJUÍ, 2012.

CARDOSO, E.; NICOLETI, G. G.. Responsabilidade social do cooperativismo: o caso da Blucredi. Revista Interdisciplinar Científica Aplicada, Blumenau, v.1, n.2, p.o1-24, 1o Sem., 2007.

CARROLL, A. B. The Pyramid of corporate Social Responsibility: toward the moral management of organizational stakeholders. Business Horizons, New York, 1991.

CHAVES, C. J. A.; VIEIRA, F. G. D.; ROCHA, E. E. R. B. Possibilidades e Limites das Ações de Responsabilidade Social em Organizações Cooperativas. In ENCONTRO DA ASSOCIAÇÃO NACIONAL DE PÓS-GRADUAÇÃO E PESQUISA EM ADMINISTRAÇÃO. Anais... São Paulo, 2009. p. 101-108. 
COSTA, E. H. Fundamentos da responsabilidade social empresarial. Rio de Janeiro: La Salle, 2007.

CRUZ, F. J. A.; CABRAL, A. C. A.; PESSOA, M. N. M.; SANTOS, S. M.; Relações entre responsabilidade social interna e comprometimento organizacional: um estudo em empresas prestadoras de serviços. Revista Brasileira de Administração Científica, jul, ago, set, out, nov, dez de 2012. ocb.org.br/site/sescoop/atuação.asp. Acesso em: 24 jan. 2014.

ETHOS, Instituto Ethos de Responsabilidade Social. Indicadores Ethos de Responsabilidade Social, 2014. Disponível em: www3.ethos.org.br/wp-content/uploads/2013/11/Indicadores-Ethos-NSR-Usoda-Ferramenta-questionrio.pdf. Acesso em: 17 out. 2016.

ETHOS, Instituto Ethos de Responsabilidade Social. Apresentação das informações gerais sobre responsabilidade social $\mathrm{e}$ as ações do instituto, 2016. Disponível em: http://www3.ethos.org.br/cedoc/responsabilidade-social-empresarial-e-sustentabilidade-para-agestao-empresarial/. Acesso em: 23 jul. 2016.

GARCIA, J. H. F.; WEBER, R. O. Estudo de Processos Trabalhistas em Cooperativas Agropecuárias da Região Central do Estado do Rio Grande do Sul. Revista de Gestão e Organizações Cooperativas RGC, Santa Maria, v. 6, n. 11, p. 217-237, Jan./Jun. 2019. DOI: dx.doi.org/10.5902/235904323326o.

GIBBERT, G.M.; BEZERRA, S.A. O cooperativismo paranaense e a responsabilidade social empresarial como fator de competitividade. Ciências Sociais em Perspectiva, (6) 10, 1ㅇem/2007.

GRAYSON, D.; HODGES, A. Compromisso social e gestão empresarial. São Paulo: Publifolha, 2002.

LAZZARESCHI, N; ALVES, P. R; BONELLI, V.V; Responsabilidade Social Empresarial: Ética nos negócios, In. ENCONTRO ANUAL DA ASSOCIAÇÃO NACIONAL DOS PROGRAMAS DE PÓS GRADUAÇÃO EM ADMINISTRAÇÃO - ENANPAD, 40, 2016, Costa do Sauípe, Anais... Costa do Sauipe: ANPAD, 2016.

LEISINGER, K. M.; SCHMITT, K Ética empresarial: responsabilidade global e gerenciamento moderno. Petrópolis: Vozes, 2001.

MARTINS, R. A. Abordagens Quantitativa e Qualitativa. In CAUCHICK MIGUEL, P. A. (Org.) Metodologia de Pesquisa em Engenharia de Produção e Gestão de Operações. Rio de Janeiro: Elsevier, 2010, cap. 3, p. 45-61.

MELO NETO, F. P.; FROES, C. Responsabilidade social e cidadania empresarial: a administração do terceiro setor. 2. ed. Rio de Janeiro: Qualitymark, 2002.

MINITAB - Statistical Software. www.minitab.com/pt-br/. Acesso em: o3 de junho 2017.

NISHIGAWA, K.S.; GIMENES, F.M.P.; GIMENES, R.M.T. A inserção da responsabilidade social no sistema cooperativista: o caso da cooperativa agrícola Consolata. Informe Gepec. v. 12, no 2, jul/dez. 2007.

NORILER, I. L. M, MACHADO, D. D. N, Análise dos indicadores de Responsabilidade Social Corporativa: Um Estudo de Caso em uma Cooperativa de Crédito, CONVIBRA - Congresso Virtual Brasileiro de Administração, 5. Anais. dez. 2008. http://www.convibra.com.br/2008/default.asp. Acesso em: 16 mar. 2017.

OCB, Organização das Cooperativas Brasileiras. Princípios Cooperativistas, 2016. Disponível em: www.ocb.org.br/site/cooperativismo/principios.asp. Acesso em 14 nov. 2016. 
OCB, Organização das Cooperativas Brasileiras. Ramos do Cooperativismo, 2019. Disponível em: www.ocb.org.br/ramos. Acesso em 13 dez. 2019.

OMAR, O-S.; ROSALEM, V.; BA, S.A.C. Equilíbrio cooperativo e governança democrática: um novo paradigma cooperativo em face da crise de identidade. Revista de Gestão e Organizações Cooperativas - RGC, Santa Maria, RS, Vol. 6, № 11, 1o Sem., p. 173-192 2019.

DOI: dx.doi.org/10.5902/2359043232448.

PICCININI, V. C., GUIMARÃES, V. N., OLIVEIRA, S. R., KOROSUE, A. Cooperativas de Trabalho: Forma de Autogestão Flexibilização Precarizada? In: ENANPAD - ENCONTRO DA ASSOCIAÇÃO NACIONAL DOS PROGRAMAS DE PÓS-GRADUAÇÃO EM ADMINISTRAÇÃO, 27, 2003, Atibaia SP. Anais., Rio de Janeiro: ANPAD, jan 2003. CD-ROM.

PONTES, A.V.V.; OLIVEIRA, L.; VIEIRA, P.C.N.; BRUCKER, S.L.S. Responsabilidade Social Interna: a percepção dos colaboradores sobre a política de remuneração, benefícios e carreira. In SEGET SIMPÓSIO DE EXCELÊNCIA EM GESTÃO E TECNOLOGIA, 13. Anais... 2016.

PORTAL do Cooperativismo Financeiro. Os 7 princípios do cooperativismo. 2016. Disponível em: cooperativismodecredito.coop.br/cooperativismo/historia-do-cooperativismo/os-7-principios-docooperativismo/. Acesso em: 19 de nov. 2016.

QUEIROZ, H. M. G, Gestão da Diversidade: Um estudo em duas Empresas Mineiras, In ENCONTRO DA ASSOCIAÇÃO NACIONAL DE PÓS-GRADUAÇÃO E PESQUISA EM ADMINISTRAÇÃO. Anais... São Paulo, 2009.

RENDÓN-COBIÁN, M.V. La responsabilidad social tácita. El caso de una hacienda y una cooperativa en el sureste de México. INNOVAR, v. 29, n. 72, p. 103-116, abril-junio del 2019.

SCHNEIDER, J. O. A doutrina do cooperativismo: análise do alcance, do sentido e da atualidade dos seus valores, princípios e normas nos tempos atuais. Revista do Centro Interdisciplinar de Desenvolvimento e Gestão Social - CIAGS \& Rede de Pesquisadores em Gestão Social - RGS, v. 3(2). p. 251-273, jul/dez. 2014.

SCHNEIDER, J. O. Democracia, participação e autonomia cooperativa. 2 ed. São Leopoldo: Unisinos, 1999.

SERRA, F.A.R.; FERREIRA, M.P.; TEIXEIRA, W.A. A responsabilidade social no Brasil: o caso da cooperativa Cocamar. Glob Advantage. Instituto Politécnico de Leiria. Leiria (PT) n 16, p. 3-32, 2008.

SILVA, A. B.; SILVA, M. C.; CHIAPINOTTO, D. M. Programa Começar Banricoop. Revista de Gestão e Organizações Cooperativas - RGC, Santa Maria, RS, Vol. p. o1-2o Edição Especial o1/2018. DOI: dx.doi.org/10.5902/2359043230551

SOUZA, P.; COELHO, K. S.; KANITZ, A. F.; GONÇALVES, H. S.; BISPO, A. C. K. A. Responsabilidade Social do Programa Empresa Saudável e qualidade de vida em uma operadora de planos de saúde de Florianópolis. HOLOS, vol. 5, p. 315-332, 2013.

SOUZA, M.M.; LAROS, J.A. Satisfação no trabalho e responsabilidade social empresarial: uma análise multinível. Revista Psicologia, Organizações e Trabalho, 10(2), 21-37, 2010.

TURRIONI, J.B.; MELLO, C.H.P. Metodologia de Pesquisa em Engenharia de Produção: Estratégias, métodos e técnicas para condução de pesquisas quantitativas e qualitativas. Itajubá: UNIFEI, 2012.

VIEIRA, S. Análise de Variância (ANOVA). São Paulo: Atlas, 2006. 